\title{
ECONOMIC THEORIES OF SETTLEMENT BARGAINING
}

by

Andrew F. Daughety and Jennifer F. Reinganum

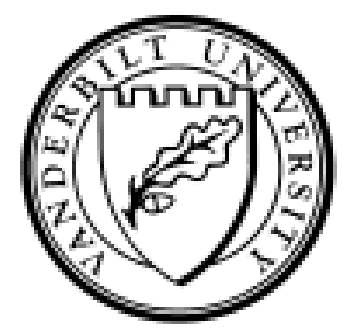

Working Paper No. 05-W08

April 2005

\section{DEPARTMENT OF ECONOMICS \\ VANDERBILT UNIVERSITY \\ NASHVILLE, TN 37235}

www.vanderbilt.edu/econ 


\title{
Economic Theories of Settlement Bargaining
}

\author{
Andrew F. Daughety and Jennifer F. Reinganum* \\ Department of Economics and Law School \\ Vanderbilt University
}

November 2004

\begin{abstract}
We briefly review two basic models of settlement bargaining based on concepts from information economics and game theory. We then discuss how these models have been generalized to address issues that arise when there are more than two litigants with related cases. Linkages between cases can arise due to exogenous factors such as correlated culpability or damages, or they can be generated by discretionary choices on the part of the litigants themselves or by legal doctrine and rules of procedure.
\end{abstract}

Keywords: Multiple litigants, externalities, asymmetric information

Suggested shortened running title: Economics of Settlement

*We thank the National Science Foundation for support via NSF Grant SES-0239908. Correspondence: Professor Andrew F. Daughety, Department of Economics, 415 Calhoun Hall, Vanderbilt University, Nashville, TN 37235. Email: andrew.f.daughety@vanderbilt.edu, jennifer.f.reinganum@vanderbilt.edu. Telephone: 615-322-3453. FAX: 615-343-8495. 


\section{Table of Contents}

Overview

Bilateral Settlement Bargaining

Externalities Induced by Litigant Discretionary Choice

Confidential Settlement

Most-Favored-Nations Clauses

Externalities Induced by Doctrinal or Procedural Rules

Collateral Estoppel and Precedent

Class Action Lawsuits

Joint and Several Liability

Insolvency

Summary 


\section{Overview}

In this article we provide a selective survey of recent work on the economics of settlement bargaining, emphasizing settings wherein there are multiple (that is, more than two) litigants. The research on multiple-litigant settlement bargaining has built on previous work on bilateral settlement bargaining, and employs the tools used therein. Thus, we first provide a brief review of the salient concepts from information economics in the bilateral settlement bargaining context.

The essential feature of multilateral bargaining is the creation or presence of externalities among the bargainers which arise because of the multiplicity of possible bargaining pairs; that is, when bargaining between two litigants is influenced by the possibility, or necessity, of simultaneous or subsequent bargaining by a litigant with other parties. Sometimes, the source of third-party influence is simply choices made in other bargains by litigants who overlap with some of those in any instant bargain. For example, a confidential settlement between an "early" plaintiff and a defendant is likely to affect the information and case viability of a "later" plaintiff suing the same defendant, if the defendant's culpability is, to some extent, correlated across the cases. Bargaining in the early suit is over both the amount of the settlement and the confidentiality of the agreement. Engaging in confidential settlement is a matter of choice by the litigants (and it may result in the payment by the defendant to the early plaintiff of "hush money" in exchange for providing confidentiality), and it affects the second bargaining pair (the later plaintiff and the same defendant). Thus, in the section entitled "Externalities Induced by Litigant Discretionary Choice," we consider some recent papers that have examined how discretionary choices by one or more of the litigants (to create, or capitalize on, possible linkages among yet other litigants) generate such externalities. In this section the preferences of the litigants over the use of such devices need not be directly opposed; in the case of confidential agreement, early plaintiffs and a defendant (common to the early and to later plaintiffs) may agree that the employment of the device is mutually advantageous (but this may or may not be true for later plaintiffs).

On the other hand, sometimes existing legal doctrine (for example, the doctrine of joint and several liability) or rules of procedure (such as collateral estoppel) may induce bargaining externalities. Of course, as in the preceding paragraph, the choice by one or another of the litigants to make use of the relevant legal doctrines or procedural rules may be voluntary, but in this case 
preferences by the individual litigants over the use of such doctrines and procedures are usually diametrically opposed; such rules exist to provide recourse when agreement is not possible. For example, rules such as those regarding the joint liability for harm by two defendants, either of whose actions may have harmed a plaintiff in a single incident, generally act to advantage the plaintiff and disadvantage the defendants. This doctrine is available for use by plaintiffs seeking damages, and its use induces externalities between the defendants in question. Thus, our last major section is entitled "Externalities Induced by Doctrinal or Procedural Rules."

\section{Bilateral Settlement Bargaining}

Hay and Spier (1998) and Daughety (2000) provide detailed reviews of settlement bargaining between two parties wherein disagreement may lead to trial. This section will provide a very brief review of the bilateral settlement bargaining literature, with special emphasis on the models used in the rest of the discussion. Early papers on this topic, such as those by Landes (1971), Gould (1973), and Posner (1973), considered settings wherein both litigants knew all relevant information. In this case, since trial is costly, both litigants are made better off by avoiding trial through agreeing to split the avoided costs. Thus, this literature provided models which predicted that no trials would occur; alternatively put, these models assert that settlement bargaining is efficient and that concluding a settlement agreement is always rational. Later decision-theoretic papers (such as Shavell, 1982) provided models wherein bargaining might collapse, thereby resulting in a trial. In this approach, trials occur when there are irreconcilable conflicts between the litigants as to assessments over the likely outcome in court. These irreconcilable conflicts reflect differences in assessments over what the outcome at trial would be, differences the parties could not eliminate even if all information was jointly known. Analyses with irreconcilable assessments driving the possibility of settlement failure are known as "inconsistent priors" analyses. Thus, the decision-theoretic models provide the possibility of inefficient settlement bargaining, but the cause of the inefficiency lies in intransigence on the part of the litigants. While inconsistent priors models are convenient to use, they have two drawbacks. First, the prediction of bargaining agreement or unresolved dispute is based on whether the individual assessments about what will happen at trial overlap or not. Thus, either a region of possible settlement exists or it doesn't, which means that more subtle 
issues of response to parameters of interest (such as the individually-incurred cost of trials, the nature of informational differences, or attributes of the trial procedure itself) may have little or no predicted effect of the outcome of the settlement negotiations. Second, from a game-theoretic perspective, inconsistent prior assessments over the outcomes of a game inject an unmodeled source of irrationality into an analysis that is based on a rational-actor paradigm; see Binmore (1992) on the conflict between Bayesian decision-making and the employment of inconsistent priors in a model of rational behavior.

Models of settlement bargaining employing game theory ${ }^{1}$ and information economics have developed over the past 20 years. In these models the bargaining agents may possess different information (called private information); if the information was common knowledge to both bargainers, there would be no barrier to settlement, but the asymmetry in what each agent knows may result in bargaining failure. The reason is that the presence of private (that is, asymmetric) information affects the strategic behavior of the bargainers; thus, such models rely on strategic response to informational differences, rather than intransigence, to provide a range of outcomes, some of which involve inefficiency. More precisely, if $A$ and $B$ are bargaining and $A$ possesses some information that is relevant to the transaction (and $B$ does not have this information, but knows that $A$ does), then in choosing bargaining strategies, both $A$ and $B$ have to account for how their opponent will modify their bargaining strategies in the light of this asymmetry. For example, a plaintiff is likely to know more about the actual damages she has suffered due to a harm from a product than is the product's manufacturer. Knowing this, and recognizing that plaintiffs have an incentive to inflate their demands, the game's equilibrium may involve the manufacturer being more resistant to higher demands than to lower ones: his willingness to go to trial is increasing in the plaintiff's settlement demand. ${ }^{2}$ This in turn feeds back to influence the plaintiff's decision about what demand to make, recognizing that higher demands are likely to elicit a higher chance of bargaining failure, leading to a costly trial. Thus, in contrast with the early ("full information") literature and in contrast with the inconsistent priors literature, trial may occur not because of intransigence, but because of rational wariness. Moreover, the equilibrium prediction provides the

\footnotetext{
${ }^{1}$ There is an enormous literature applying game theory to general bargaining problems; one recent summary can be found in Muthoo (1999).

${ }^{2} \mathrm{Or}$, in an alternative analysis, a manufacturer is likely to be better informed as to his likely liability. Thus, in bargaining, defendants might understate their culpability, and plaintiffs will be more resistant to accepting lower offers.
} 
likelihood of trial as a specific function of the distribution of damages (and/or degree of culpability), and the attributes of the parties involved.

Bebchuk (1984) and Reinganum \& Wilde (1986) provided what are now viewed as the canonical models of settlement bargaining employing tools from game theory and information economics. Both models assume that one party is better informed about a salient fact (or facts) than is the other party. Let us construct a simple example to understand these two (complementary) approaches to modeling settlement bargaining. Assume a consumer bought a product from a manufacturer and the consumer has been harmed by the product. The consumer sues the manufacturer for damages; the consumer is the plaintiff, denoted $P$, and the manufacturer is the defendant, denoted $D$. Moreover, for ease of discussion, assume that the parties agree that $D$ will be found liable with probability $p$, but that damages (denoted $d$ ) are $P$ 's private information. This is not unreasonable, since $P$ is likely to be better informed as to her damages than is $D$. We refer to $P$ as the "informed" party and to $D$ as the "uninformed" party. $P$ 's possible levels of damages (alternatively, the possible values of her private information) are called $P$ 's types To fill in the details of the model, assume: 1) $D$ 's conjecture as to the possible values of the actual damages follows a distribution $F(d)$, with $d$ ranging between a lowest possible value, $d_{L}$, and a highest possible value, $\left.d_{H} ; 2\right)$ this distribution is commonly known to $P$ and $D$ and has an associated density denoted $f(d) ; 3)$ each party must pay their own court costs, denoted $t_{P}$ for $P$ and $t_{D}$ for $D$ (respectively), if bargaining fails and they must go to trial (for convenience, let aggregate court costs be $T=t_{P}+t_{D}$ ), and that these trial costs are commonly known; and 4) at trial the court can correctly determine the true level of damages (which is the private information $P$ possesses). ${ }^{3}$

To understand the Bebchuk analysis ${ }^{4}$, assume that the bargaining follows a very simple structure: $D$ makes a settlement offer, $s$, to $P$, who then either accepts the offer (resulting in $s$ dollars transferred from $D$ to $P$ ) or rejects the offer (thereby going to trial, where the court awards damages $d$ with probability $p) .{ }^{5}$ For $P$ 's threat to go to trial to be credible, we require that $p d_{L} \geq t_{P}$;

\footnotetext{
${ }^{3} \mathrm{~A}$ variety of papers in the literature weaken or manipulate some of these assumptions.

${ }^{4}$ In Bebchuk's paper the private information was about liability, while in Reinganum \& Wilde's paper the private information concerned damages. To make the comparisons between the models straightforward, we pose both applied to the case of privately-known damages.

${ }^{5}$ More complex models with counter-proposals are possible, but if we focus on the last stage of any such finitehorizon process, it has the form of an offer/demand followed by a response, followed either by settlement or trial. Note that, in contrast with the standard bargaining literature, it is plausible to posit a last stage since defendants have an incentive to delay, thereby necessitating that courts set a deadline.
} 
that is, the net expected payoff for the type with the lowest possible damages is non-negative. This last assumption can be relaxed, but doing so complicates the exposition unnecessarily. Such bargaining games, wherein the uninformed player moves first, are called "sorting" (or "screening") models because the demand made by the uninformed player acts to sort the second-mover's types into those who will accept the offer and those who will reject it. This means that whatever the initial distribution of possible damage levels (the distribution of possible types of $P$, denoted above as $F$ ), the model can provide a prediction as to the resulting likelihood of settlement or trial, and the expected returns and costs associated with the bargaining process.

$D$ 's objective is to make an offer which minimizes total expected trial and settlement costs. Since there is a continuum of $P$ 's types between $d_{L}$ and $d_{H}$, then an offer $s$ that sorts these types into two groups will make some type, denoted $\widetilde{d}$ (called the "marginal type"), just indifferent between the offer $s$ and going to trial, where that type would obtain $p \widetilde{d}-t_{P}$. Alternatively put, the offer $s$ picks out the marginal type $\widetilde{d}=\left(s+t_{P}\right) / p$. On the other hand, if this type were to choose to go to trial, $D$ 's cost at trial would be $p \widetilde{d}+t_{D}$. Therefore, we can think of $D$ 's problem as making an offer (that is accepted by some type $\widetilde{d}$, and by all of those types with lesser damages than $\widetilde{d})$ so that expected costs are minimal. This is formalized as the following optimization problem:

$$
\min _{\widetilde{d}} \int_{\widetilde{d}}^{d_{H}}\left(p x+t_{D}\right) f(x) d x+F(\widetilde{d})\left(p \widetilde{d}-t_{P}\right)
$$

The first term is the expected cost to $D$ from going to trial, because all types above $\widetilde{d}$ will reject the offer $s=p \widetilde{d}-t_{P}$ (they can do better at trial). In the integral, $D$ 's cost at trial for any such type is weighted by the likelihood that $D$ is of that type. The second term above is the expected cost of settlement to $D$ since all types at and below $\widetilde{d}$ accept the offer $p \widetilde{d}-t_{P}$ (they do no better, and most do worse, at trial). The term $F(\widetilde{d})$ weights the offer by the fraction of types who will accept it Once the marginal type $\widetilde{d}$ that minimizes this total expected cost is found (denoted as $d^{*}$, the solution to equation (1)), the optimal offer by $D$ is $s^{*}=p d^{*}-t_{P}{ }^{6}$

Figure 1 illustrates the equilibrium in a sorting model for the case where possible damage levels are uniformly distributed (that is, all values of $d$ are equally likely, so $f(d)=1 /\left(d_{H}-d_{L}\right)$ ). Solving the problem in (1) above, one can show that the marginal type of interest, $d^{*}$, is $d_{L}+T / p$ (as shown

\footnotetext{
${ }^{6}$ This is an equilibrium as long as the limits on the integral are not violated, so $d^{*}$ must be less than $d_{H}$.
} 
of $\mathrm{P}$

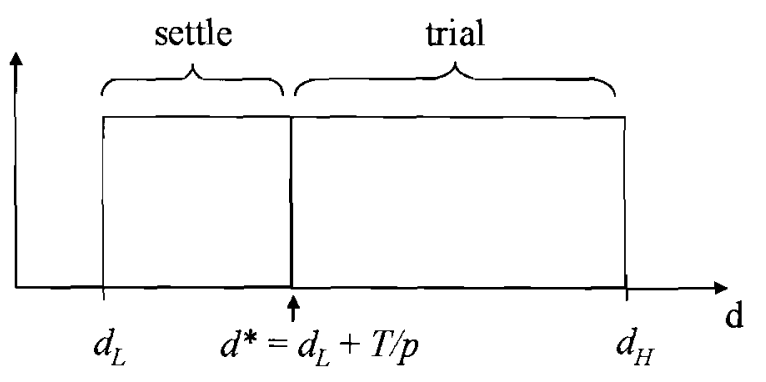

Figure 1: Equilibrium in a Sorting Model
Possible levels of P's harm (P's possible types)

in the figure), so the equilibrium offer is $s^{*}=p d^{*}-t_{P}=p d_{L}+T-t_{P}=p d_{L}+t_{D} \cdot{ }^{7}$ Thus the likelihood of settlement is $F\left(d^{*}\right)=\left(d^{*}-d_{L}\right) /\left(d_{H}-d_{L}\right)=(T / p) /\left(d_{H}-d_{L}\right)<1$, the likelihood of trial is $\left(d_{H}-d_{L}-T / p\right) /\left(d_{H}-d_{L}\right)>0$, and the expected total trial cost is $T\left(d_{H}-d_{L}-T / p\right) /\left(d_{H}-d_{L}\right)$; this last item is the social cost associated with the presence of asymmetric information. Notice also that the distribution of types going to trial is just a truncated version of the original distribution of types, $F$. Thus, the model predicts that cases with low levels of damages will settle while only those with sufficiently high levels of damages will proceed to trial.

This model provides a number of other implications; we list a few here. ${ }^{8}$ First, an increase in the range of stakes (that is, an increase in $d_{H}-d_{L}$ or an increase in $p$ ) or a decrease in either litigant's court costs leads to a reduction in the likelihood of settlement. Second, redistribution of court costs from one litigant to the other (that is, adjustments in $t_{P}$ and $t_{D}$, holding $T$ fixed) has no impact on the likelihood of settlement or on the magnitude of the social cost. Third, a cap on damages (if modeled as a reduction in $d_{H}$ ) leads to a reduction in the likelihood of trial and a reduction in the social costs associated with bargaining (of course this does not account for the fact that $P$ 's with very high damages would be undercompensated).

In the Reinganum \& Wilde model, the informed party moves first and the uninformed party

\footnotetext{
${ }^{T}$ The requirement that $d^{*}<d_{H}$ means that, for sorting to be an equilibrium, we require $p\left(d_{H}-d_{L}\right)>T$. That is, the range of the expected stakes should exceed the total court costs.

${ }^{8}$ For example, one could also consider the impact of parameter changes on each litigant's payoff, but this would add unnecessarily to the length of this discussion.
} 
now considers the demand made and decides whether to accept or reject the offer (again, rejection leads to trial). This type of model is called a "signaling" model because the first mover signals information via their settlement offer. Returning to the example outlined earlier, $P$ would make an demand, with higher demands reflecting a $P$ with greater harms suffered. Now $D$ must be wary of high demands from a $P$, as a low-damaged $P$ would also like to make such a demand if $D$ would mistakenly assume that damages awarded at trial would be high. Thus, $D$ rationally rejects higher offers more frequently (that is, $D$ is willing to go to trial with a higher likelihood for demands which are higher). It is the equilibrium wariness of $D$ that deters mimicry and results in the signal being informative (that is, the signal provides useful information about $P$ 's type to $D$ when $D$ is trying to decide what is likely to happen at trial, and whether to reject the offer from $P)$.

While somewhat more technically demanding (see Reinganum \& Wilde 1986 for details), the basics of the model are that $P$ makes a demand and $D$ uses the demand to update his assessment of which type of $P$ he is likely to go to trial against, should bargaining break down. Thus, for any demand $S, D$ forms beliefs $b(S)$ as to which type (or types) would have made such a demand. $D$ then decides whether to accept or reject the demand employing these beliefs: $D$ accepts the demand $S$ if and only if $S \leq p b(S)+t_{D}$. Let $D$ 's probability of rejecting demand $S$ be denoted as $r(S)$. Since $P$ must choose $S$ recognizing that she will go to trial against $D$ if he rejects her demand, $P$ 's problem is to choose $S$ to maximize her return:

$$
\max _{S} S(1-r(S))+\left(p d-t_{P}\right) r(S)
$$

where the first term reflects settlement at $S$, which occurs with probability $1-r(S)$, while the second term reflects $P$ 's return if she goes to trial. Under mild conditions there is a revealing equilibrium, wherein a $P$ of type $d$ makes the equilibrium demand $S^{*}(d)=p d+t_{D}$ and $D^{\prime}$ s beliefs are correct (the type who would make such a demand is a $P$ who has damages $d$, that is, $\left.b\left(S^{*}(d)\right)=d\right)$. Furthermore, $D$ 's equilibrium rejection function, $r^{*}(S)$, is zero at the lowest type's revealing demand, $S_{L} \equiv S^{*}\left(d_{L}\right)=p d_{L}+t_{D}$, is increasing and concave in $S$, and reaches a maximum value, which is less than 1 , at the highest type's revealing demand, $S_{H} \equiv S^{*}\left(d_{H}\right)=p d_{H}+t_{D}$. This 


\section{Frequency of}

rejection of

P's demand

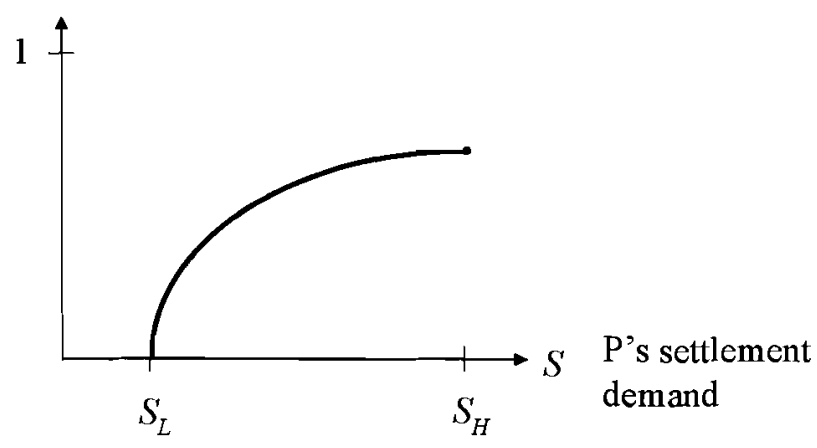

Figure 2: D's Equilibrium Strategy in a Signaling Model

rejection function is illustrated in Figure $2,{ }^{9}$ again for the earlier example involving a continuum of uniformly distributed types of possible damage levels for $P$.

In contrast with the sorting model, notice that one implication of the signaling model is that (except for $d=d_{L}$ ), all types have a positive chance of going to trial, with that chance increasing with the level of damages (since the settlement demand is increasing in the true level of damages). Moreover, the distribution of types who go to trial is different from the distribution of types who have been harmed: in the example, the initial distribution of types was a uniform distribution, but the resulting distribution implied by the rejection function shown in Figure 2 is weighted towards higher types. Comparative statics results similar (in direction) to those found in the sorting model can be obtained as well.

A number of analyses have expanded on these two basic approaches (again, see Daughety, 2000, or Hay \& Spier, 1998); such analyses usually assume one-sided asymmetric information. Twosided analyses are rarer (that is, $P$ and $D$ each possess some private information), primarily for two reasons. First, if both sides have private information (perhaps $P$ knows the actual level of harm suffered better than $D$ and $D$ knows its culpability better than $P$ ), the analysis becomes more complex. Schweizer (1989), considering two types for each litigant, and Daughety \& Reinganum (1994), allowing for a continuum of types for each litigant, have examined two-sided settlement bargaining. The basic result is that the first-mover signals some or all of his information, which

\footnotetext{
${ }^{9} r^{*}(S)=1-\exp \left\{-\left(S-S_{L}\right) / T\right\}$.
} 
acts to sort the second mover, thereby revealing some of her information (though it is too late for the first-mover to take advantage of it); thus, the resulting analysis is a composition of the two more basic structures. Second, a one-sided model simply asserts that one party has an informational advantage over the other, so if a two-sided issue can be viewed in terms of a net informational advantage for one or the other party (for example, one party has more information concerning expected damages, the product of liability likelihood and actual damages, than the other party), then assuming that the information asymmetry is one-sided may not be unreasonable.

\section{$3 \quad$ Externalities Induced by Litigant Discretionary Choice}

\subsection{Confidential Settlement}

Imagine that a plaintiff, $P_{1}$, has been harmed by a product ${ }^{10}$ produced by a defendant, $D$. $P_{1}$ may suspect that others may have been harmed as well (that is, there may be other plaintiffs $P_{2}, P_{3}$, etc.), but these harmed individuals might have suffered their losses at other times and places, so perhaps there is little or no chance for $P_{1}$ to find these other plaintiffs so as to pursue, say, a class-action suit. ${ }^{11}$ Moreover, even if there were some way to locate others who may have been harmed, the existence of substantial issues of law might preclude the formation of a class. ${ }^{12}$ Instead, when $P_{1}$ and $D$ bargain, a confidential settlement, wherein the details (and possibly even the existence) of the agreement are kept secret, might be mutually advantageous. The law provides for such secrecy either via court-authorized sealing, or through "contracts of silence" which specify stipulated damages should the plaintiff violate the confidentiality agreement. The central economic questions are: 1) how does the possibility of bargaining over both money and confidentiality affect the likelihood of settlement and the settlement amounts (if agreement is reached); and 2) how does the availability of confidentiality, as a bargaining option, influence the welfare of all litigants (including that of possible future plaintiffs). The basic results are threefold. First, confidentiality

\footnotetext{
${ }^{10}$ We restrict discussion to the products liability context for concretenss of the analytical results, but as has become apparent in the popular press, confidentiality has figured into a variety of other concerns (e.g., public health and sexual abuse of minors).

${ }^{11}$ Suppressing the ability of plaintiffs to share information, such as might be obtained via discovery, appears to be a major purpose of protective orders used in a variety of cases; see Hare et al. (1988).

${ }^{12}$ See Judge Richard Posner's majority opinion in In re Rhone-Poulenc Rorer Inc., 51 F.3d 1293 (7th Circuit), wherein the Court de-certified a class-action lawsuit partly due to problems of discerning a common set of negligence standards across multiple jurisdictions.
} 
improves the likelihood of settlement and raises the expected settlement amount reached between $P_{1}$ and $D$. In this sense, the early plaintiff obtains "hush money" to help the defendant suppress information, if so doing helps reduce the likelihood of suits by later plaintiffs. Second, the degree of correlation of $D$ 's culpability (and, therefore, liability) across the individual plaintiffs' cases influences the degree to which confidentiality may reinforce or undermine deterrence. Such a correlation is "weak" when $D$ 's actions may have led to conditions contributing to the separate harms, but wherein each case may have substantially different issues of causation to prove. Thus, for example, $D$ 's chemical spill may have contributed to $P_{1}$ 's lung cancer and to $P_{2}$ 's brain tumor, but informationally, the only value $P_{2}$ obtains from knowing about the case between $P_{1}$ and $D$ is that the spill may have a role in $P_{2}$ 's harm. On the other hand, suppose that $D$ is a national gasoline retailer, with a chain of gas stations around the country, all employing the same design for underground tanks for gasoline storage. Then while precise local geological conditions might also affect the likelihood of leakage of gasoline into the water table, a high likelihood of liability in one case (a community $P_{1}$ versus $D$ ) is likely to imply a high likelihood of liability in any other case (another community $P_{2}$ versus $D$; see Ashcraft $v$. Conoco). Such a degree of correlation of the cases is called "strong."13 As shown in Daughety \& Reinganum (1999, 2002), if the cases are weakly correlated, then even though $D$ has private information regarding his culpability, both $P_{1}$ and $D$ have the same expected value for $D$ 's future expenditures due to settlement negotiations or trial with future plaintiffs. Thus, it is possible for the early plaintiff's bargain to extract (as hush money) enough of a payment from $D$ so as to make the defendant face the same expected costs for potential harms as would occur without confidentiality: under weak correlation, deterrence need not be reduced. On the other hand, in the case of strong correlation, the fact that $D$ 's culpability is common to the two cases makes D's costs in the continuation game (the future suits) dependant upon this information, which means that $P_{1}$ cannot efficiently extract the full value of confidentiality she provides to $D$. Therefore, under strong correlation, deterrence is undermined. These two results lead to the third, namely, that if correlation is weak, the average plaintiff (that is, a plaintiff who is equally likely to be early or late) may prefer the availability of confidentiality as a bargaining option, but if case correlation is strong, the average plaintiff is strictly worse off

\footnotetext{
${ }^{13}$ But again, the early case is assumed not to be fully determinative of what will occur in a later case. If it were, then we would think in terms of collateral estoppel, wherein liability in one case means liability in the next; see Section 4 below.
} 
when confidentiality is available than when it is forbidden.

We briefly consider some of the details of the strong correlation case. Daughety \& Reinganum (2002) consider a model wherein $D$ sequentially bargains with two plaintiffs $\left(P_{1}\right.$ followed by $\left.P_{2}\right)$ over both the amount of each plaintiff's settlement and (in the case of $P_{1}$ ) whether to keep the settlement details confidential. ${ }^{14}$ Assume that $P_{1}$ has already filed suit against $D$ (note that confidentiality can be used to suppress this information as well), and that while $P_{2}$ has not yet filed a suit, she is more likely to do so if she becomes aware of $P_{1}$ 's suit. ${ }^{15}$ The analysis considers three possible outcomes for the bargaining game between $P_{1}$ and $D: 1$ ) a confidential agreement specifying a transfer from $D$ to $P_{1}$ and that both parties would keep all details secret; 2) an "open" agreement specifying a transfer from $D$ to $P_{1}$, wherein the details of the agreement are publicly available; and 3) a trial if bargaining fails to reach one of the preceding agreements, with a publicly-available record. The authors assume that associated with each possible outcome there is a probability that $P_{2}$ will become aware that she, too, should sue $D$. Moreover, since the cases are strongly correlated, to the degree that the outcome of the first suit provides information about $D$ 's culpability in the second case, this information will influence $P_{2}$ 's beliefs about the type of $D$ she faces as well, possibly influencing the demand she might make in her own settlement bargaining process.

Each possible outcome initially implies a level of publicity associated with the first case, and therefore the likelihood of triggering the second suit. Let the given (incremental) probabilities referred to above are denoted $\gamma_{i}, i=C, O, T$. The probabilities reflect the "publicity effect" of each possible bargaining outcome, so that one should expect that $\gamma_{L}<\gamma_{C}<\gamma_{O}<\gamma_{T}$; where $\gamma_{L}$ is the "background" probability that $P_{2}$ would realize she has a case against $D$ even if there were no suit filed by $P_{1}$. That is, $P_{2}$ is least likely to sue $D$ after a confidential settlement between $D$ and $P_{1}$, more likely to sue if the agreement is open, and yet more likely if the bargaining fails and a trial results (even if $D$ is found not liable since we are not assuming collateral estoppel, $P_{2}$ can still win her case even if $P_{1}$ lost). This assumption reflects the impact of confidentiality on the suppression of information that might encourage or facilitate future suits against the same defendant.

Sequential bargaining is modeled as a series of screening games, but now the outcome of the first

\footnotetext{
${ }^{14}$ Yang (1996) reports results from a model of correlated damages in which the settlement amount is (exogenously) sealed and finds that if the litigation costs are high, then D is willing to offer even more to settle the first suit (and deter the filing of the second suit), while if litigation costs are low, then confidentiality results in less settlement.

${ }^{15}$ For example, $P_{2}$ may not initially be aware that the harm she has suffered might be due to $D$ 's product or to D's culpability.
} 
screening game potentially signals information to the participants in the second screening game. This means that $D$ will be interested in reducing the information signaled; $P_{1}$ recognizes this and is able to extract more money from $D$ for providing confidentiality. Since this leads to a lower possibility of $P_{2}$ collecting compensation from $D$, this effectively means that $P_{1}$ extracts money from $P_{2}$ via the settlement with $D$. Alternatively put, the first case generates a positive externality to $P_{2}$ (and a negative externality to $D$ ) by raising her awareness of $D$ 's involvement in her harm, but $P_{1}$ cannot directly charge $P_{2}$ for this "service," so instead she charges $D$ for controlling the size of the negative externality (that is, his expected losses due to a suit from a later plaintiff). ${ }^{16}$ For example, if $P_{1}$ were to make a high, open demand of $D$, then there would be a substantial transfer of information to $P_{2}$ because this would provoke a large number of $D$ types to choose trial (at which $D$ 's type is revealed). Since making such a high demand is costly to $P_{1}$ (as she is very likely to go to trial) and she cannot charge $P_{2}$ for the information, it cannot be an equilibrium for $P_{1}$ to make a high open demand. Instead, it is optimal for $P_{1}$ to offer to settle, and to do so confidentially, but to make a settlement demand that extracts the value of confidentiality as well as possible. This extraction is not perfect since $D$ has private information, and thus is able to retain some of the gains.

Let $p$ denote the probability that $D$ is liable; assume that $p$ is distributed uniformly on $\left[p_{L}, p_{H}\right]$ and that it is the same for both cases (this is strongly correlated culpability); moreover, assume that only $D$ knows $p$. In each screening bargaining game, the plaintiff makes a demand, which is accepted by $D$ types with sufficiently high values of $p$, and rejected by those with lower values of $p$. As in Section 1, we can define settlement demands and marginal types associated with an open settlement and a confidential settlement in the first case (denoted $s_{O}$ and $p_{O}$, and $s_{C}$ and $p_{C}$, respectively). These expressions can be ordered as follows: $s_{C}>s_{O}$ and $p_{C}<p_{O}$ (see Figure 3 below). That is, the equilibrium settlement demand and the likelihood of settlement are both higher under confidentiality than under openness. This is because confidentiality creates a gain for $D$ in which $P_{1}$ can share: despite $P_{1}$ 's higher confidential settlement demand, more defendant types are willing to accept it. This provides "cover" for $D$ in his subsequent bargaining game with $P_{2}$. While the signal does affect $P_{2}$ 's beliefs about the types of $D$ who might have settled,

\footnotetext{
${ }^{16}$ As indicated earlier, strong correlation means that $P_{1}$ 's expectation about the future costs to $D$ will not, in general, be the same as $D$ 's.
} 
in equilibrium it does not affect $P_{2}$ 's equilibrium demand. ${ }^{17}$ However, because confidentiality also suppresses publicity (relative to an open settlement and, especially, to trial) that might have triggered $P_{2}$ 's suit, $P_{2}$ is worse off when $P_{1}$ and $D$ settle confidentially. Finally, a plaintiff behind the veil of ignorance (with an equal chance of becoming $P_{1}$ or $P_{2}$ ) is worse off under confidentiality, so the gain to $P_{1}$ is more than offset by the loss to $P_{2}$. Nevertheless, it can be shown that total expected litigation costs are lower when confidential settlement is permitted.

Thus, in sum, the foregoing analysis suggests that confidentiality should be expected to lower overall litigation costs, but is not Pareto superior to openness. This has not accounted for privacy considerations (such as valid privacy concerns for individual plaintiffs, or valid trade secrecy issues for firms), which undoubtedly makes some confidential agreements welfare-enhancing. However, the fact that its availability as a bargaining tool makes the early negotiating parties better off at the expense of later plaintiffs suggests that one cannot rely on the arguments that the early parties might make for maintaining secrecy without examining the question of how likely it is that a sequence of cases is likely to exist, and whether any culpability by the defendant in such a sequence is likely to be strongly correlated.

\subsection{Most-Favored-Nation Clauses}

A second linkage across seemingly bilateral settlement negotiations occurs when settlement bargains may use a "most-favored-nations" clause; the implications for settlement bargaining of this clause have been explored in papers by Spier (2003a,b) and Daughety \& Reinganum (2004). The term "most-favored nations" (MFN) derives from international relations, and has evolved to mean an agreement between two countries that stipulates that one country was to obtain the "best" trading relationship possible (e.g., the lowest tariffs) among the other's trading partners. This is a nondiscrimination clause: if $\mathrm{A}$ and $\mathrm{B}$ have a trading agreement which includes an MFN clause, and if $\mathrm{A}$ comes to an agreement with $\mathrm{C}$, the MFN clause means that $\mathrm{B}$ would never be treated by $\mathrm{A}$ to worse terms of trade than those available to C. ${ }^{18}$ The implementation of the clause is simple: should C obtain better terms of trade from A than does B, A would have to refund the difference

\footnotetext{
${ }^{17}$ This is because it was assumed that $D$ 's culpability was exactly the same in the two cases; if culpability was less strongly correlated, then the equilibrium demand in the second case would be changed as well.

${ }^{18}$ Most-favored-customer clauses provide the parallel notion in consumer markets, where a customer is promised that they will be offered the lowest price offered to any other customer.
} 
to $\mathrm{B}$. This removes the incentive for $\mathrm{A}$ to provide $\mathrm{C}$ with better terms than are provided to $\mathrm{B}$, or to make those terms available to B as well. Note that, while the relationships between A and B and between $\mathrm{A}$ and $\mathrm{C}$ are bilateral in nature, the MFN clause creates a multilateral relationship. Under some circumstances it primarily provides a benefit to the common player (here, A) and, under other circumstances, it primarily provides a benefit to the early, non-common player (here, B).

The agreements reached between the tobacco industry and the states in the mid-to-late nineties (see Viscusi 2002 for the background on this industry and the agreements) provides an interesting example of two different (but related) uses of an MFN clause in a collection of settlement agreements. ${ }^{19}$ Over a period of a few years, four states reached agreements with the tobacco industry; Mississippi settled in 1997 for $\$ 3.6$ billion, Florida settled in 1997 for $\$ 11.3$ billion, Texas settled in 1998 for $\$ 15.3$ billion and Minnesota settled in 1998 for $\$ 6.6$ billion. All four states had pursued a novel legal theory that the firms in the industry owed the states restitution for past health expenditures made by each state on behalf of smokers, and all four agreements contained MFN clauses. The MFN clauses in the Mississippi, Florida and Texas agreements were triggered by the Minnesota settlement (yielding MFN payments of $\$ 550$ million, $\$ 1.8$ billion and $\$ 2.3$ billion, respectively). The remaining 46 states shortly thereafter signed the Master Settlement Agreement, which also contained an MFN clause, now to make sure that all the states would join the one agreement. ${ }^{20}$ This suggests two possible motivations which we explore briefly below. One is that early (non-common) players (e.g., the individual states) may propose MFN clauses as a means of obtaining later payments; for reasons to be made clear below, we will refer to this as a "leverage" motive. The other motive is that the common player may propose an MFN clause so as to reduce delay and to improve commitment power on its behalf; we will refer to this as the "delay-reduction" motive, and we discuss it first.

Spier (2003a,b) considers the following multi-litigant bargaining scenario. Consider a defendant, $D$, facing a large number of plaintiffs who have individually suffered harms of different magnitudes due to the use of $D$ 's product. Thus, for example, the rectangular density shown in Figure 1 earlier might represent the different harms of a large number of plaintiffs (rather than representing

\footnotetext{
${ }^{19}$ For discussions of this example and a variety of other settlement examples using MFNs, see the previously cited papers by Spier and by Daughety \& Reinganum.

${ }^{20}$ The MSA did not trigger the earlier MFN clauses for the first four states.
} 
alternative levels of harm for a single plaintiff). Here the harm each plaintiff has suffered is her own private information and $D$ is uninformed with respect to this information (though $D$ knows the distribution of plaintiffs' harm). $D$ is contemplating settling with some of these plaintiffs and going to trial against the remainder, so the problem is one of screening. Moreover, bargaining in this model may occur over time, and delay in reaching an agreement is costly to all; for convenience, assume that there are now two possible rounds of bargaining. Consider the following strategy for $D: \quad D$ makes an offer to settle, perhaps making the offer $s^{*}$ shown in Figure 1 . Now in the screening analysis in Section 2, such an offer was a one-time, take-it-or-leave-it offer. However, if some plaintiffs settle at $s^{*}$ and others do not, then D's second offer will be higher than $s^{*}$, so as to further screen those plaintiffs who might go to trial under $s^{*}$ (in the Figure, those to the right of $d^{*}$ ). Of course, if the first group of plaintiffs recognizes that $D$ will subsequently raise the offer, then they will not agree to $s^{*}$, but will instead wait for the improved offer. This results in delay, which is assumed to be costly. Without the commitment power implicit in the one-time-only structure of the original Bebchuk-style screening analysis, $D$ faces the possibility of having to make an increasing sequence of offers, which clearly would be inferior to the one-time-only offer which minimized overall cost, namely $s^{*}$.

Spier (2003a) shows that an MFN clause eliminates the incentive for $D$ to make the higher second offer, as an offer of $s^{*}$ with an MFN clause means that any plaintiff who accepts $s^{*}$ now will also obtain any increase associated with any later offer accepted by other plaintiffs, so no plaintiff has an incentive to wait. This is because $D$ would not find it in his interest to make a higher offer later (and make the associated incremental payments to those who settled with an MFN clause), making the one-time offer of $s^{*}$ credible. Spier shows that using an MFN is advantageous for $D$, by allowing $D$ to commit to his cost-minimizing offer $s^{*}$, and thereby eliminating delay in reaching an agreement (hence, the "delay-reduction" motive); the MFN provides $D$ with a degree of monopoly power, as he no longer competes for settling plaintiffs with his future (second-round) self. Thus, the defendant who is facing a mass of plaintiffs with private information about their damages will always prefer to incorporate an MFN in the settlement offer. Spier also compares the likelihood of settlement, the welfare of plaintiffs, and the total costs of litigation between a setting wherein an MFN is allowed, and one wherein it is not. In keeping with the notation in the earlier section on bilateral bargaining, let the probability density describing the expected harm be denoted as 
$f(\cdot)$; Figure 1 shows an $f$ which is constant. Spier (2003a) shows that the likelihood of settlement and plaintiff welfare improve (respectively: decline; stay constant) if $f$ is increasing (respectively: decreasing; stays constant) in value at the point of the first-period marginal type when an MFN clause is precluded..$^{21}$ Thus, Figure 1 illustrates a type of "watershed" example, as $f$ is constant everywhere. Distributions with rising densities will imply that an MFN improves the settlement rate and is preferred by plaintiffs, while those distributions with declining densities yield the reverse results.

Daughety \& Reinganum (2004) consider the second motivation for using an MFN, which we referred to as a "leverage" motivation. Consider a version of Spier's setup (a defendant who is uninformed about the damages individual plaintiffs have suffered), but now limit the number of plaintiffs to two, and assume there is an early plaintiff $\left(P_{1}\right)$ and a later plaintiff $\left(P_{2}\right)$. Furthermore, assume that the bargaining between each plaintiff and the common defendant is modeled as a signaling game (see Section 2): in period one the informed $P_{1}$ makes a settlement demand of $D$, and either there is agreement or trial, followed by period two, wherein the informed $P_{2}$ makes a demand of $D$, which again may result in agreement or trial. Without an MFN, the sequential pair of signaling games behaves just like a sequence of Reinganum \& Wilde games as illustrated in Figure 2 in Section 2 above.

Now, assume that $P_{1}$ and $D$ conclude an agreement which contains an MFN, and that the settlement amount was $S_{1}$. This now affects what $P_{2}$ can hope to obtain in her settlement negotiations with $D . \quad P_{2}$, who might have suffered a greater harm than the first plaintiff, knows that if $D$ were to pay $P_{2}$ her full damages plus $D$ 's court costs (i.e., the amount that would be demanded in the no-MFN case), then this would generate an MFN payment to $P_{1}$, and $D$ might be better off simply going to trial, since a judgment at trial does not trigger an MFN payment (while a higher settlement does). Thus, D's rejection function is now progressively higher for all demands by $P_{2}$ above $S_{1}$. Hence, for demands she might make above $S_{1}, P_{2}$ moderates her demand to account for the higher likelihood of rejection that the MFN has now created. This means that when $P_{2}$ does make a (moderated) demand above $S_{1}$, then sometimes it is accepted by $D$ and an MFN payment is made to $P_{1}$ as well, and sometimes it is rejected by $D$. So $P_{1}$ is distinctly better

\footnotetext{
${ }^{21}$ More limited results hold for total litigation and trial costs: these are decreasing when the settlement rate is increasing or constant, but may move in either direction if the settlement rate is decreasing.
} 
off because of the expected MFN payment. But $P_{1}$ 's benefit from an MFN does not stop there, since the possibility of the MFN payment means that there is a lower incentive for low types of $P_{1}$ to try to mimic the higher types, because they have more to lose if they are rejected by $D$. This, in turn, means that $D$ need not reject $P_{1}$ 's demand with as high a probability as would be used if there were no MFN payment possibility. Thus, $P_{1}$ can make the same demand as she would have before and this demand is rejected with a lower likelihood. Figure 4 illustrates the modifications to Figure 2 that are caused by inclusion of an MFN clause.

In sum, the expected value of an MFN clause to $P_{1}$ reflects two effects: 1 ) the expected MFN payment and 2) the reduced likelihood of bargaining failure. This is referred to as a "leverage" motive because the first plaintiff is able to use an MFN clause and her role as an early-settling player to leverage an advantage, extracting money due to the presence of the later plaintiff. Not surprisingly, $P_{2}$ is always worse off, in expectation, due to the demand-moderating effect of the MFN and the potential increased likelihood of bargaining breakdown. ${ }^{22}$. However, as Daughety \& Reinganum show, overall litigation costs may fall with the use of an MFN. Thus, while not Pareto superior (since it would be opposed by the second plaintiff), the use of an MFN may be welfare-enhancing, when viewed from the perspective of reducing total litigation costs.

As is illustrated by the settlements between the states and the tobacco industry discussed earlier, MFNs may reflect both leverage and delay-reduction purposes, and different multilateral bargaining settings may result in agreements using such clauses for one or both reasons. Significantly, as both analyses have shown, the use of an MFN may improve welfare (at least in a litigation-cost reduction sense) and might be Pareto-improving (under the conditions discussed earlier in the delay-reduction setting). This is in contrast with the use of "most-favored-customer" clauses in monopoly and oligopoly pricing, which have generally been found to be welfare-reducing (as their use generally enhances monopoly or cartel power).

\footnotetext{
${ }^{22}$ Note that, second plaintiffs with harms that are less than those suffered by the first plaintiff will make smaller demands than $S_{1}$, and face the no-MFN rejection probability, and therefore will not be affected by the presence of an MFN clause.
} 


\section{Externalities Induced by Doctrinal or Procedural Rules}

\subsection{Collateral Estoppel and Precedent}

Collateral estoppel makes a ruling in one case binding in subsequent related cases. For instance, if a driver is found liable for the injuries to the driver of another car, the passenger in the victim's car may argue that she need not separately establish the first driver's liability; rather, she may assert that collateral estoppel already establishes liability, and only the passenger's damages remain to be determined. It is a matter of judicial discretion to determine whether collateral estoppel applies in a given situation. This doctrine thus establishes a link between cases brought by different plaintiffs that might otherwise not exist.

Another example is a government antitrust prosecution that establishes a firm's liability for the harms associated with its anticompetitive behavior. According to Briggs et al. (1996, p. 770;

hereafter BHM), "Section 4 of the Clayton Act permits a private plaintiff to use findings from a prior antitrust suit brought by the government to pursue a treble damage suit against the same defendant for the same conduct." In this case, the statute specifically authorizes the application of collateral estoppel. Subsequent civil suits for damages need not re-litigate the firm's liability, as this has already been established by the government suit; the harmed parties need only demonstrate and document the extent of their harms.

BHM examine equilibrium settlement behavior in a sequence of suits. First, there is a government suit where the defendant's type (a "violator," denoted $V$, or "non-violator," denoted $N V$ ) is his private information. The defendant has an opportunity to make a settlement offer, to which the government may respond with settlement, trial, or by dropping the case; thus, this is a signaling game as discussed in Section 2. If the government suit goes to trial and establishes the defendant's liability, or if the defendant settles (which is taken as an admission of liability in their model), then a private plaintiff will file suit and settle (since her damages are also assumed to be common knowledge). However, if the government drops its suit, then the defendant's liability has not been established; indeed, a rational (Bayesian) private plaintiff will lower her subjective belief that the defendant will be found liable in the future, which may deter the filing of her suit. If the private plaintiff is not deterred, then a similar bargaining game occurs between the defendant and the private plaintiff; however, while the government bears its own trial costs, the private plaintiff's trial 
costs are shifted to the defendant if the private plaintiff prevails at trial. So the question is how the possibility of a follow-on suit by a private plaintiff affects the defendant and the government's settlement behavior in the first suit.

First consider a single suit between the government $(G)$ and the defendant $(D) . \quad D$ is in violation of antitrust laws (that is, he is of type $V$ ) with probability $p$; D's type is his private information, while $p$ is commonly known by $D$ and $G$.. Let $d_{G}$ represent the damages that $G$ will receive if she prevails at trial. Let $t$ denote the cost of trial for each litigant; for simplicity, we assume this is the same for $D, G$, and the private plaintiff $P$. The following parameter restriction is maintained: (A1) $p d_{G}-t>0$. BHM show that the equilibrium takes the following form. $G$ files suit; a $D$ who is of type $N V$ makes no offer to settle while a $D$ of type $V$ mixes between making no offer and making the lowest offer that would be acceptable to $G$ if $D$ were known to be liable $\left(s=d_{G}-t\right.$; we will call this a "serious" offer). $G$ responds to a serious offer by accepting it, and responds to no offer by mixing between trial and dropping the case.

Let $\tau_{G}$ denote $\operatorname{Pr}\{$ trial $\mid$ no offer $\}$ and let $\eta_{G}$ denote $\operatorname{Pr}\{$ no offer $\mid V\}$. In order for $G$ to be willing to randomize between trial and dropping the case following no offer, it must be that $\left[p \eta_{G} /(1-\right.$ $\left.\left.p+p \eta_{G}\right)\right] d_{G}-t=0$. The left-hand-side is $\operatorname{Pr}\{V \mid$ no offer $\}$ (which is found using Bayes' Rule) times the amount collected $\left(d_{G}\right)$ from a $D$ of type $V$, minus $G$ 's trial costs, while the right-handside is the value of dropping the case. Similarly, in order for a $D$ of type $V$ to be willing to randomize between making no offer and offering $d_{G}$, it must be that $\tau_{G}\left(d_{G}+t\right)=d_{G}-t$. The left-hand-side is $\operatorname{Pr}\{$ trial|no offer $\}$ times the award $D$ must pay plus his trial costs, while the righthand-side is the value of making a serious settlement offer, which is accepted for sure. Solving yields $\tau_{G}^{*}=\left(d_{G}-t\right) /\left(d_{G}+t\right)$ and $\eta_{G}^{*}=t(1-p) / p\left(d_{G}-t\right)$; these are fractional given (A1).

Now consider the filing decision; $G$ expects the equilibrium payoff $p\left\{\left(1-\eta_{G}^{*}\right)\left(d_{G}-t\right)+\eta_{G}^{*} \tau_{G}^{*}\left(d_{G}-\right.\right.$ $t)\}-t(1-p) \tau_{G}^{*}$ from filing suit. That is, with probability $p, D$ is of type $V$, and $G$ collects the amount $d_{G}-t$ if either (a) $D$ makes a serious offer; or (b) $D$ makes no offer and $G$ takes $D$ to trial. With probability $1-p, D$ is not of type $V$ and therefore makes no offer, but $G$ goes to trial with probability $\tau_{G}^{*}$; since $D$ has not violated the law, $G$ simply loses its trial cost $t$. Substituting the equilibrium values $\tau_{G}^{*}$ and $\eta_{G}^{*}$ and simplifying allows us to verify that this equilibrium payoff reduces to $p d_{G}-t$, which is positive by (A.1). Thus, anticipating that the game will play out in an equilibrium fashion, it is optimal for $G$ to file suit. 
Now suppose that there is a potential follow-on suit by a private plaintiff $P$; let $d_{P}$ denote $P$ 's damages. BHM show that many of the properties of the previous case continue to hold. In particular, a $D$ who is not of type $V$ makes no offer to $G$. If $D$ has been revealed to be of type $V$ (either by trial or settlement in the government suit), then $P$ files suit, and settles for the amount $d_{P}$ (this is because the value of her damages is common knowledge, and the type $V$ defendant would bear $P$ 's trial cost). $G$ continues to mix between going to trial and dropping the case when no offer is made, and this pins down $\eta_{G}=\operatorname{Pr}\{$ no offer $\mid V\}$ at the same value as before. Thus, the probability of settlement is unaffected by the potential for a follow-on suit. A $D$ of type $V$ continues to mix between no offer and the same serious offer $\left(d_{G}-t\right)$ to $G$, but the payoffs are now adjusted by the additional costs (of the second suit) that accompany both settlement and trial. If $P$ would not file suit following a dropped suit by $G,{ }^{23}$ then for $D$ to be indifferent between making no offer and settling (first with $G$ and then with $P$ ), it must be that $\tau_{G}^{* *}\left(d_{G}+t+d_{P}\right)=d_{G}-t+d_{P}$, or $\tau_{G}^{* *}=\left(d_{G}-t+d_{P}\right) /\left(d_{G}+t+d_{P}\right)$. Note that $\tau_{G}^{* *}>\tau_{G}^{*}$; in equilibrium, $G$ will go to trial more often following no offer when there is a potential follow-on suit by a private plaintiff.

There are two important features of this model that one might consider changing. First, it is assumed that settlement with the government establishes the defendant's liability (i.e., it is an admission of liability). This may be plausible for a government suit, but it is generally possible in civil suits to settle and still deny liability, in which case collateral estoppel cannot be invoked by a party to a subsequent related suit. Second, the government here considers only its own damages $d_{G}$; its objective does not reflect compensation received by the private plaintiff. Nevertheless, the government does become a tougher bargainer (in the sense that it takes the defendant to trial more often) when there is a potential follow-on suit. This occurs because when there is a potential follow-on suit, settlement (which includes an admission of liability) becomes less attractive to the defendant; in order to restore the defendant's indifference between settlement and making no offer (which must obtain in equilibrium), the government must take the defendant to trial more often following no offer; thus, $G$ becomes tougher.

Che \& Yi (1993; hereafter CY) provide a model in which settlement does not imply an admission of liability. In CY, a defendant faces a sequence of two plaintiffs, and the decision regarding the

\footnotetext{
${ }^{23}$ This will occur when $q d_{P}-(1-q) t<0$, where $q=t / d_{G}$ is the private plaintiff's posterior probability that the defendant is of type $V$, given no offer was made in the government suit. See BHM for the analysis of the case wherein the private plaintiff would file suit following a dropped suit by the government.
} 
defendant's liability in the second case is positively correlated with the decision in the first case. Although re-litigation of a common issue is either estopped or not, based on judicial discretion, the model of correlated decisions might be viewed as a situation in which both litigants in the first suit have symmetric but imperfect information about whether the judge in the second suit will find the first decision precedential. CY ask how this correlation of outcomes in a sequence of trials affects litigants' incentives to settle. They find that a defendant with a high likelihood of being found liable in the first case will be more eager to settle so as to avoid setting an unfavorable precedent, while a defendant with a low likelihood of being found liable in the first case will be more eager to go to trial so as to set a favorable precedent, for the next case.

In each suit, it is assumed that the plaintiff has private information about her damages, the probability that the plaintiff will prevail is common knowledge, and the defendant makes a takeit-or-leave-it settlement offer. Thus, this is a screening game in the taxonomy of Section 2. CY first examine a context in which precedent plays no role; for example, a single suit in which the probability that the plaintiff will prevail is given by $p_{1}$. From the analysis of Section 2, we know that the marginal plaintiff type is $d^{*}=d_{L}+T / p_{1}$ and the equilibrium probability of settlement is $F\left(d^{*}\right)=T / p_{1}\left(d_{H}-d_{L}\right)$. Then they consider a sequence of two suits, with the following linkage between the plaintiffs' probabilities of prevailing at trial. Let $p_{1}$ denote the probability that plaintiff $P_{1}$ will prevail at trial. Then the probability that plaintiff $P_{2}$ will prevail at trial, denoted $p_{2}$, is some base probability $p_{0}$ (independent of $p_{1}$ ) which is potentially modified by the outcome of the first suit. In particular, $p_{2}=p_{0}+\epsilon$ if $P_{1}$ won her suit; $p_{2}=p_{0}$ if $P_{1}$ settled her suit; and $p_{2}=p_{0}-\epsilon$ if $P_{1}$ lost her suit, where $\epsilon>0$. CY refer to this as a "mutual and symmetric" precedential effect; they consider alternative versions in their paper. This probability structure is common knowledge to all of the litigants.

Consider settlement negotiations in the second suit, conditional on the first suit's outcome. Using the analysis from Section 2, we know that the marginal type in the second suit will be defined by $d_{2}^{*}=d_{L}+T / p_{2}$, and the associated likelihood of settlement will be $F\left(d_{2}^{*}\right)=T / p_{2}\left(d_{H}-d_{L}\right)$. From this, it is clear that the likelihood that the second suit will settle is highest when $P_{1}$ lost her suit and lowest when $P_{1}$ won her suit. Notice that if $P_{1}$ settled her suit, then $P_{2}$ faces the same probability of prevailing as if there were no $P_{1}$; that is, $P_{1}$ 's suit has no precedential effect. In addition, $D$ 's expected costs in the second suit (denoted $\left.C_{j}, j=W, S, L\right)$ are highest when $P_{1}$ won 
her suit $(W)$ and lowest when $P_{1}$ lost her suit $(L)$; that is, $C_{W}>C_{S}>C_{L}$.

In considering what offer to make to $P_{1}$, the defendant recognizes the impact that $P_{1}$ 's decision regarding settlement will have on $D$ 's continuation payoff in his suit with $P_{2}$. Since $P_{1}$ is a nonrepeat player, her decision regarding settlement is determined by the same criterion as if there were no $P_{2}$; that is, a $P_{1}$ with damages of $d$ will accept any settlement offer $s \geq p_{1} d-t_{P}$. However, $D$ now anticipates future costs of $C_{S}$ if $P_{1}$ accepts his offer, and future costs of $C_{T}=p_{1} C_{W}+\left(1-p_{1}\right) C_{L}$ if $P_{1}$ rejects his offer and trial occurs. These future costs are added to the usual costs associated with settlement and trial, respectively. Modifying the objective function given in Section 1 to reflect these continuation costs, the subsequent analysis implies that the marginal type in the first suit is given by $d_{1}^{*}=d_{L}+\left(T+C_{T}-C_{S}\right) / p_{1}$, and the probability that the first case settles is given by $F\left(d_{1}^{*}\right)=\left(T+C_{T}-C_{S}\right) / p_{1}\left(d_{H}-d_{L}\right)$.

To determine the effect of the second suit on settlement behavior in the first suit, we compare the equilibrium probabilities of settlement in the first suit with and without the second suit. Recall that the probability of settlement in the first suit when there is no $P_{2}$ is given by $F\left(d^{*}\right)=T / p_{1}\left(d_{H}-d_{L}\right)$. It follows that $F\left(d_{1}^{*}\right) \geq F\left(d^{*}\right)$ if and only if $C_{T} \geq C_{S}$. Given the ordering of $D$ 's expected costs in the second suit, $C_{T}$ is an increasing function of $p_{1}$ which starts out below $C_{S}$ and ends up above $C_{S}$. Thus, there is a unique value $p^{*} \in(0,1)$ such that the presence of $P_{2}$ results in a greater likelihood of settlement when $p_{1}>p^{*}$ (since $D$ would then like to reduce his exposure to trial where he faces a relatively high risk of establishing an unfavorable precedent) and a lower likelihood of settlement when $p_{1}<p^{*}$ (since $\mathrm{D}$ is then more willing to risk trial, where he faces a relatively high chance of establishing a favorable precedent). ${ }^{24}$

\subsection{Class Action Lawsuits}

Rule 23 of the Federal Rules of Civil Procedure authorizes the formation of a class action lawsuit. In a class action lawsuit, a small number of named plaintiffs litigate on behalf of a very large number of similarly-harmed individuals. It is a matter of judicial discretion as to whether the individuals' harms are sufficiently similar as to be aggregated into a class (i.e., whether the class

\footnotetext{
${ }^{24}$ Choi (1998) provides a model in which two imitators consider entering the market of an incumbent patentholder. A finding of patent validity (or invalidity) in an infringement suit against the first entrant is presumed to apply equally to the second entrant. He finds that the patentholder may accommodate (rather than sue) the first entrant to avoid a finding of patent invalidity. Accommodation plays the same role as settlement, as it avoids the setting of any precedent.
} 
will be "certified"). For instance, if a defendant's product has injured many consumers, then the issue of liability may be the same in each case. Pursuit of judicial economy and stability of the law suggests that this issue should be litigated once and for all. Moreover, the scale economies achievable for plaintiffs, whose individual harms might otherwise not rationalize a suit, can help ensure that victims receive compensation and defendants face the costs generated by their behavior, thus inducing more appropriate precaution.

If the extent of harm is also similar, then this too could be determined once and for all. If the extent of harm differs widely among the victims, then it may be that the class is certified only for the issue of liability determination, but each individual must pursue a separate suit for damages. In most cases, participation in the class is voluntary; that is, individuals can "opt out" of the class and pursue their claims directly against the defendant. Thus, an interesting question arises when damages are somewhat heterogeneous, but nevertheless a class action has been certified to determine both liability and damages for the entire class. In this case, the award at trial may result in "damages averaging;" that is, a lump-sum amount may be awarded to the plaintiff class, to be distributed in equal shares. In this event, those class members with relatively high damages will be under-compensated, while those with relatively low damages will be over-compensated. Thus, a potential class member who anticipates that she will be under-compensated may be tempted to opt out; on the other hand, by doing so she will have to bear the full costs of her suit against the defendant. Moreover, if a class member with comparatively high damages opts out, this lowers the average damages within the class and (assuming scale economies in litigation) raises the costs of each remaining member.

Thus, multiple externalities are involved when individual suits are aggregated into a single suit. Scale economies in litigation costs represents a positive externality, but others are more ambiguous. As mentioned above, if each class member receives the average damages, then highdamaged plaintiffs suffer a negative externality from the presence of low-damaged plaintiffs in the class and low-damaged plaintiffs enjoy a positive externality from high-damaged plaintiffs in the class. Finally, since each member is bound by the same liability decision at trial, there may be similar externalities if there is some heterogeneity in the probability of each plaintiff prevailing in an individual suit.

Che (1996) provides a formal model of the formation of a class action, and the subsequent 
settlement negotiations between the class (or an opt-out) and a single defendant. He first examines a model in which the strength of individual claims (which may be viewed as a product of the likelihood of prevailing and the extent of damages), though heterogeneous, are observable. For simplicity, he considers only two plaintiff types, those with "high stakes" and those with "low stakes." If plaintiffs' types are observable, he finds that (under plausible conditions) there is always a Nash equilibrium in which all high-stakes plaintiffs opt out, while all low-stakes plaintiffs join the class. Next, Che considers a model in which each plaintiff's type is her private information vis-a-vis the defendant and other plaintiffs, but is learned by the court at trial (at least on average). In this case, it turns out that it is no longer a dominant strategy for low-stakes plaintiffs to join the class. Whether it is advantageous for a single plaintiff (of either type) to join the class depends on which other plaintiffs are joining it. If only those with low stakes are joining the class, then joining the class sends a signal of weakness to the defendant, who may subsequently make a low settlement offer, while not joining the class sends a signal of strength to the defendant, perhaps inducing a high settlement offer. If only those with high stakes are joining the class, then joining the class sends a signal of strength to the defendant, who may subsequently make a high settlement offer, while not joining the class sends a signal of weakness to the defendant, perhaps inducing a low settlement offer.

The timing of the model is as follows. First, each plaintiff simultaneously and non-cooperatively decides whether to join the class action or to opt out; once made, this decision is irreversible. Moreover, it is assumed that no plaintiff can be excluded from the class. If a suit is brought (either by a class or an individual plaintiff), the defendant makes a take-it-or-leave-it settlement offer which the plaintiff either accepts or rejects. At trial, the court learns the individual plaintiff's harm, or the average harm of the plaintiff class, and awards this amount. Che assumes that any settlement obtained by the class will also be shared equally among its members. Thus, all class members will agree about whether to accept or reject a given settlement offer.

Formally, denote the expected damages award for a high-stakes $P$ by $d_{H}$ and the expected damages award for a low-stakes $P$ by $d_{L}$. There is a unit mass of plaintiffs, and the fraction of high-stakes $P$ s is given by $\mu \in(0,1)$. Let $t_{0}$ denote $P$ 's trial costs for an individual suit and let $t(k)$ denote trial costs per capita for members of a class action if $k$ is the fraction of all plaintiffs who join the class. Per capita trial costs are assumed to be a continuous and strictly decreasing 
function of $k$ with $t(0)=t_{0}$. On the other hand, Che limits the extent of scale economies by assuming that $t_{0}-t(1)<d_{H}-d_{L}$; that is, the cost savings associated with litigating as a member of the complete class versus litigating alone is less than the difference in the stakes. ${ }^{25}$ Finally, let $t_{D}$ denote $D$ 's trial costs in an individual suit.

Che considers the following benchmarks. First, he solves the (bilateral) settlement negotiations model for the case in which each $P$ litigates separately and has private information regarding her stakes. This is a screening game in the taxonomy of Section 2, since the uninformed party $D$ makes the settlement offer. There are only two types of $P$, and thus there are only two offers that $D$ should contemplate making: $s_{H} \equiv d_{H}-t_{0}$, which would be accepted by both plaintiff types, and $s_{L} \equiv d_{L}-t_{0}$, which would be accepted by $P$ s with low stakes, but rejected by $P$ s with high stakes. $D$ 's expected payoff from offering $s_{H}$ is $d_{H}-t_{0}$ and $D$ 's expected payoff from offering $s_{L}$ is $\mu\left(d_{H}+t_{D}\right)+(1-\mu)\left(d_{L}-t_{0}\right)$. Therefore, it is optimal for $D$ to offer $s_{H}$ (that is, to pool rather than sort the plaintiff types) when the fraction of $H$ types is sufficiently high; specifically, when $\mu \geq \mu^{*} \equiv\left(d_{H}-d_{L}\right) /\left(d_{H}-d_{L}+t_{0}+t_{D}\right)$.

Second, he considers both individual and class action suits, but under the assumption that $D$ can observe $P$ 's type. With respect to case-by-case negotiations, $D$ offers $s_{H} \equiv d_{H}-t_{0}$ to an individual $P$ of type $H$ and $s_{L} \equiv d_{L}-t_{0}$ to an individual $P$ of type $L$. Since this is exactly what each $P$ expects from going to trial, these offers are accepted. In the class action setting, let $\alpha$ denote the fraction of $H$-type plaintiffs in a class action, and let $\beta$ denote the fraction of $L$-type plaintiffs in a class action. Then $\alpha \mu+\beta(1-\mu)$ is the fraction of all plaintiffs who join the class. Using Bayes' Rule, $\rho(\alpha, \beta)=\alpha \mu /(\alpha \mu+\beta(1-\mu))$ is the fraction of class members that are of type $H$, while $1-\rho(\alpha, \beta)=\beta(1-\mu) /(\alpha \mu+\beta(1-\mu))$ is the fraction of class members that are of type $L$.

Then $D$ will offer each member of the class the amount $s_{C}(\alpha, \beta) \equiv \rho(\alpha, \beta) d_{H}+(1-\rho(\alpha, \beta)) d_{L}-$ $t(\alpha \mu+\beta(1-\mu))$. This amount is the expected per capita damages for members in the class less the per capita litigation costs, and is the lowest offer that is still acceptable to the members of the class. When deciding whether to join the class, a $P$ of type $L$ (respectively, $H$ ) simply compares $s_{C}(\alpha, \beta)$ to $s_{L}$ (respectively, $s_{H}$ ). It is clear that $s_{C}(\alpha, \beta) \geq s_{L}$ since the expected per capita

\footnotetext{
${ }^{25}$ If this assumption does not hold, then scale economies due to class membership are so strong that there will always be an equilibrium in which all plaintiffs join the class. Regardless of this assumption, there is always a Nash equilibrium in which no plaintiff joins the class only because she expects no other plaintiff to join the class; this equilibrium is ruled out by using "trembling-hand perfection" as an equilibrium refinement (see Mas-Colell, Whinston and Green, 1995, p. 299).
} 
damages must be at least $d_{L}$ and $t(k)<t_{0}$ for $k>0$. Thus, $\beta^{*}=1$; that is, all $L$-type $P$ s join the class in equilibrium. Whether an $H$-type $P$ joins the class depends on the anticipated behavior of the other $H$-type $P$ s. There are three candidates for an equilibrium: (1) no $H$-type $P$ joins the class; (2) all $H$-type $P$ s join the class; and (3) a fraction $\alpha^{*}$ of $H$-type $P$ s join the class.

Candidate (1) is an equilibrium if and only if $s_{C}(0,1)=d_{L}-t(1-\mu) \leq s_{H}=d_{H}-t_{0}$, which is implied by the maintained assumptions that $t(k)$ is decreasing in $k$ and $d_{H}-d_{L}>t_{0}-t(1)$. Thus, there is always an equilibrium in which only $L$-type $P$ s join the class. Candidate (2) is an equilibrium if and only if $s_{C}(1,1)=\mu d_{H}+(1-\mu) d_{L}-t(1) \geq s_{H}=d_{H}-t_{0}$; that is, if and only if $\mu \geq \mu^{* *}=1-\left(t_{0}-t(1)\right) /\left(d_{H}-d_{L}\right)$, where $\mu^{* *}>\mu^{*}$ is assumed. Thus, if the fraction of $H$-type $P$ s is large enough, then the dilution of the per capita damages award caused by the participation of $L$ types is sufficiently low that it can be outweighed by the scale effects on litigation costs. Finally, if $\mu \geq \mu^{* *}$, then there is a Candidate (3) equilibrium as well, with $\alpha^{*}$ defined uniquely by $s_{C}\left(\alpha^{*}, 1\right)=s_{H}$; this equality ensures that an $H$-type $P$ is indifferent between joining the class and opting out. Thus, there can be an equilibrium in which some high-stakes plaintiffs join the class action, while others opt out.

Now we can consider the more complex bargaining problem faced by a defendant who observes only the kind of suit he faces (and, if it is a class action suit, the fraction of all plaintiffs who have joined the class), and the more complex participation decision of a plaintiff who is equally uninformed about her fellow plaintiffs' stakes. Both of these litigants will be acutely interested in the posterior probability that a $P$ is of type $H$, given that she has chosen to join the class or to opt out, respectively. Recall that $\alpha$ denotes the fraction of $H$-type plaintiffs that join the class, $\beta$ denotes the fraction of $L$-type plaintiffs that join the class; thus $\alpha \mu+\beta(1-\mu)$ is the fraction of all plaintiffs who join. In the previous discussion, $\alpha$ and $\beta$ were assumed to be observable; here they are conjectures about the class participation strategy used by each type of $P$; nevertheless, they can be manipulated in the same way as before, using Bayes' Rule, to find the relevant posterior probabilities. As before, $\rho(\alpha, \beta)=\alpha \mu /(\alpha \mu+\beta(1-\mu))$ is the posterior probability that a randomlydrawn class member is of type $H$. Analogously, $\delta(\alpha, \beta)=(1-\alpha) \mu /((1-\alpha) \mu+(1-\beta)(1-\mu))$ is the posterior probability that a randomly-drawn opt-out is of type $H$.

Thus, upon encountering a class action suit with membership $\alpha \mu+\beta(1-\mu)$, the defendant makes the same per capita settlement offer as he did when plaintiff types were observable: $s_{C}(\alpha, \beta)=$ 
$d_{H} \rho(\alpha, \beta)+d_{L}(1-\rho(\alpha, \beta))-t(\alpha \mu+\beta(1-\mu))$. Since this offer is accepted by all class members (since they expect the same payoff from trial), we can denote the payoff of each class member (given that her fellow plaintiffs use the participation strategies $\alpha$ and $\beta)$ by $V_{C}(\alpha, \beta)=s_{C}(\alpha, \beta)$.

The effect of private information becomes apparent when we consider opt-outs. When plaintiff types were observable, $D$ knew exactly how much he needed to offer to induce each $P$ to settle. When they are unobservable, $D$ faces a screening problem. Upon encountering an individual suit filed by an opt-out, there are still only two offers that $D$ should consider: $s_{H} \equiv d_{H}-t_{0}$, which would be accepted by both plaintiff types, and $s_{L} \equiv d_{L}-t_{0}$, which would be accepted by $P$ s with low stakes, but rejected by $P$ s with high stakes. $D$ 's expected payoff from offering $s_{H}$ remains $d_{H}-t_{0}$, while $D$ 's expected payoff from offering $s_{L}$ is now $\delta(\alpha, \beta)\left(d_{H}+t_{D}\right)+(1-\delta(\alpha, \beta))\left(d_{L}-t_{0}\right)$. Now it is optimal for $D$ to offer $s_{H}$ whenever $\delta(\alpha, \beta) \geq \mu^{*}$. We can summarize the plaintiffs' payoffs from opting out as follows: $V_{H}(\alpha, \beta)=d_{H}-t_{0}$; while $V_{L}(\alpha, \beta)=d_{H}-t_{0}$ if $\delta(\alpha, \beta) \geq \mu^{*}$ and $V_{L}(\alpha, \beta)=d_{L}-t_{0}$ if $\delta(\alpha, \beta)<\mu^{*}$.

Incomplete information has a substantial effect on the kinds of participation equilibria that can exist. In particular, it is no longer possible for an equilibrium to exist in which all $L$-type $P$ s join the class and all $H$-type $P$ s opt out (recall that this kind of equilibrium always exists when information is complete). For if all $L$-type $P \mathrm{~s}$ (and no $H$-type $P$ s) are expected to join the class, then not joining the class is a clear signal of type $H$ and would elicit a settlement offer of $s_{H}$; but then any $P$ of type $L$ would want to defect from joining the class to opting out. Similarly, there cannot be an equilibrium in which all $H$ types (and no $L$ types) join the class, for then $L$ types are revealed by opting out, and would want to defect to joining the class, both to receive a higher settlement offer and to enjoy the lower litigation costs.

The kinds of equilibria that do exist depend on the fraction $\mu$ of $H$-types in the plaintiff population. For $\mu \geq \mu^{*}$, there is an equilibrium in which the class action fails to form. To see this, suppose that no $P$ joins the class; then the pool of opt-outs has $\mu \geq \mu^{*}$ and thus it is optimal for $D$ to offer $s_{H}$ to any $P$ who opts out. Since this is at least as high a payoff as any $P$ could expect from joining the class (as its lone member), opting out is a best response to everyone else opting out (and this is robust to small trembles, so long as the opt-out pool has $\mu \geq \mu^{*}$ ). However, for $\mu>\mu^{*}$ there are also equilibria in which some, but not all, of each plaintiff type joins the class. ${ }^{26}$

\footnotetext{
${ }^{26}$ For this to be an equilibrium, the posterior probability that an opt-out is of type $H$ must be high enough to
} 
If $\mu>\mu^{* *}$ then, as before, there is an equilibrium in which all plaintiffs join the class. Finally, if $\mu<\mu^{*}$, there is a unique equilibrium in which no $H$ types join the class, and $L$ types split between opting out and joining the class in such a way that $D$ is just indifferent between offering $s_{H}$ and $s_{L}$ to opt-outs. ${ }^{27}$

Thus, incomplete information can cause a class action to fail to form when it would have arisen under complete information; in addition, a class action can form in which both some high-stakes $P$ s and some low-stakes $P$ s opt out because opting out can be (rationally) interpreted by $D$ as a signal of strength. Finally, a class action can form that involves only $L$-type $P$ s, but not all of them (as compared to the complete information equilibrium involving all, and only, $L$-type $P$ s). Here, although all $L$-type $P$ s would be better off if they could commit to joining the class action (in which case they could enjoy larger scale economies in litigation), this configuration cannot be supported in equilibrium for the reasons described above.

In a subsequent paper, Che (2000) considers a model that is quite similar to the preceding one, but with several significant differences; he remarks that this model is more appropriate for joinders with a small number of plaintiffs, rather than large class actions. The differences from the preceding model include: (1) there are finitely many plaintiffs rather than a continuum, so the actions of each plaintiff are non-negligible; (2) there are no scale economies associated with joinder; (3) each member of the joinder will receive her correct damages at trial; and (4) the members of the joinder can decide internally (and contract over) how to allocate money received in settlement. The defendant knows only the distribution of plaintiffs' damages, but each plaintiff knows her own damage level. The incentives for collective negotiation are then examined under two different assumptions about the information regime within the joinder: (a) all members costlessly observe all other members' damages; and (b) each member's damages remain her private information within the joinder as well.

The analysis of bargaining with an opt-out is the same as above. It is optimal to offer $s_{H}=$ $d_{H}-t_{0}$ whenever the posterior probability of $H$-type $P$ s in the pool of opt-outs is $\geq \mu^{*}$. Under

warrant the defendant offering $s_{H}$ to an opt-out (that is, $\delta\left(\alpha^{* *}, \beta^{* *}\right) \geq \mu^{*}$; otherwise the $L$ types should all join the class). Moreover, both types of $P$ must be indifferent between joining and opting out; that is, $V_{C}\left(\alpha^{* *}, \beta^{* *}\right)=s_{H}$, or $\rho\left(\alpha^{* *}, \beta^{* *}\right)=\left(d_{H}-d_{L}+t\left(\alpha^{* *} \mu+\beta^{* *}(1-\mu)\right)-t_{1}\right) /\left(d_{H}-d_{L}\right)$. There is a continuum of $\left(\alpha^{* *}, \beta^{* *}\right)$ pairs that satisfy these two relationships.

${ }^{27}$ In this equilibrium, $D$ offers $s_{H}$ with a probability denoted $\gamma^{* *}$. If the $L$ types are willing to split, then they must be indifferent between $V_{C}\left(0, \beta^{* *}\right)=d_{L}-t\left(\beta^{* *}(1-\mu)\right)$ and the mixture $\gamma^{* *} s_{H}+\left(1-\gamma^{* *}\right) s_{L}$; that is, $\gamma^{* *}=\left(t_{1}-t\left(\beta^{* *}(1-\mu)\right) /\left(d_{H}-d_{L}\right)\right.$. 
the assumption that members' damages are costlessly observed within the joinder, and that they can contract on the internal allocation of a settlement, each member will insist on receiving at least what she would receive at trial. Knowing this, all high-stakes $P$ s will join since they can receive at most $s_{H}=d_{H}-t_{0}$ by opting out (either in settlement or at trial). But then, as argued above, not joining is taken by $D$ as a clear signal of weakness (and would be followed by an offer of $s_{L}$ ),

so $L$-types will join as well. Thus, the equilibrium involves all $P$ s joining their cases. Notice how different this is from the result above wherein, under the same informational circumstances, damages averaging could generate an equilibrium in which a class fails to form, despite the scale economies in litigation assumed in that model. This does not happen here, because $H$ types' payoffs are not dragged down by the participation of $L$ types.

When a $P$ 's damages are private information even within the joinder, then every $P$ will be tempted to claim to be of type $H$. The joinder can resolve this issue by resort to mechanism design theory. A mechanism specifies whether to accept a settlement offer $s$, and how to divide it among the members of the joinder, based on their reported types. For details of how the optimal mechanism is derived, see Che (2000). In brief, it entails the $L$ types receiving "information rents" to induce them to forebear claiming to be of type $H$ and to truthfully reveal that they are of type $L ; H$ types do not have an incentive to claim to be $L$ types, so they receive no information rents. This means that some settlement offers that would be acceptable were all types observable are now rejected; only settlement offers that are high enough to cover both the aggregate expected payoff from trial plus the required information rents will be accepted. Thus, the joinder will be a tougher bargainer (i.e., will require a higher settlement offer) when it faces this internal allocation problem under asymmetric information. When the choice regarding participation is considered, it remains an equilibrium for all $P$ s to join their cases.

\subsection{Joint and Several Liability}

Joint and several liability may apply when multiple tort-feasors act concurrently or in concert to cause a plaintiff's injury. For example, two firms that dump hazardous waste into a single waterway may harm the health of people living downstream. Under joint and several liability, a plaintiff suing both defendants may collect the full amount of the damages if she prevails against either or both of the defendants at trial. In contrast, under non-joint (several only) liability, a 
plaintiff can collect from each defendant only that portion of the harm that is attributable to that defendant. Thus, joint and several liability introduces externalities between the defendants that would not exist under non-joint liability; these externalities manifest themselves both at trial and in settlement negotiations.

The classic analysis of the impact of joint and several liability (hereafter JSL) on incentives to settle was provided by Kornhauser \& Revesz (1994a; hereafter, KR). They consider a model in which a single plaintiff sues two defendants under complete, but imperfect, information about whether the defendants will be found liable. The assumption of complete information immediately suggests that there should be no trials in equilibrium, but this turns out to be false. Rather, they show that both cases will go to trial (respectively, settle) when the correlation between the defendants' likelihoods of being found liable is sufficiently low (respectively, high).

In describing settlement under JSL, we need to be specific about several other issues. In particular, we will assume the unconditional pro tanto setoff rule, which specifies that if one defendant settles, then the amount of the settlement is deducted from what the plaintiff can hope to obtain from trial against the remaining defendant. Although this is the most commonly-employed setoff rule, others do exist, notably the proportional setoff rule, which specifies that the plaintiff can obtain from the second defendant at trial the maximum of (1) the harm attributable to him and (2) the total harm less the amount of the settlement with the first defendant; and conditional versions of each of these rules, where the relevant setoff applies only if the first defendant would have been found liable had he not settled. Moreover, we will assume that a settling defendant's liability is terminated; that is, the other defendant may not seek further contribution from the settling defendant.

Assume that there are two defendants, each of whom has contributed equally to the plaintiff's harm; let the plaintiff's total harm be denoted $2 d$. Each defendant suffers a trial cost of $t$, while the plaintiff suffers a trial cost of $t$ per defendant; thus, there are no scale economies for the plaintiff in going to trial against both defendants. Finally, assume that each defendant is capable of paying the full damages $2 d .^{28}$ Let $p$ denote the probability that the plaintiff prevails when

\footnotetext{
${ }^{28} \mathrm{KR}$ allows unequal contributions by the defendants to the plaintiff's harm, scale economies in the plaintiff's trial costs, different setoff rules, and a different selection rule when multiple equilibria exist. In Kornhauser \& Revesz (1994b) they consider partially-insolvent defendants and find that (for the case of equal contribution) this increases the parameter range over which settlement occurs.
} 
she goes to trial against a single defendant, and let $\delta p$ denote the probability that the plaintiff prevails against the second defendant, having prevailed against the first, when she goes to trial against both defendants. The parameter $\delta$ varies between $\delta=1$ and $\delta=1 / p$. When $\delta=1$ the probability of prevailing against both defendants is $p^{2}$ (that is, the cases are uncorrelated) while when $\delta=1 / p$ thus the probability of prevailing against both defendants is $p$ (that is, the cases are perfectly correlated). In general, when the plaintiff goes to trial against both defendants she has a probability $\delta p^{2}$ of prevailing against both defendants, and a probability $2 p(1-\delta p)$ of prevailing against one defendant; in either case, she collects the full amount $2 d$.

The timing of the game is as follows: the plaintiff makes a settlement demand of the pair of defendants, denoted $\left(s_{1}, s_{2}\right)$. Simultaneously and non-cooperatively, each defendant decides whether to accept or reject the settlement demand made of him. Finally, any defendant who rejects his demand is taken to trial by the plaintiff. We first characterize the Nash equilibrium strategies in the subgame following receipt of the settlement demands, and then determine the plaintiff's optimal demands. In the sequel, we will denote the plaintiff by $P$ and the defendants by $D_{1}$ and $D_{2}$.

Given a pair of demands $\left(s_{1}, s_{2}\right)$, it will be a Nash equilibrium for both $D_{1}$ and $D_{2}$ to accept their respective demands if and only if $s_{i} \leq p\left(2 d-s_{j}\right)+t$, for $i=1,2$. This is because, given that $D_{j}$ is expected to accept $s_{j}, D_{i}$ can expect to pay the total harm less the amount of the settlement with $D_{j}$, should $D_{i}$ be found liable at trial (which occurs with probability $p$ ); in addition, $D_{i}$ will pay trial costs of $t$. Thus, $D_{i}$ will prefer to accept any settlement demand $s_{i} \leq p\left(2 d-s_{j}\right)+t$.

Given a pair of demands $\left(s_{1}, s_{2}\right)$, it will be a Nash equilibrium for $D_{i}$ to accept $s_{i}$ and $D_{j}$ to reject $s_{j}$ if and only if $s_{i} \leq .5 \delta p^{2}(2 d)+p(1-\delta p)(2 d)+t$ and $s_{j} \geq p\left(2 d-s_{i}\right)+t$. This is because, given that $D_{j}$ is expected to reject $s_{j}$ and go to trial, $D_{i}$ can choose to go to trial as well, in which case $D_{i}$ can expect to pay his share (half) of the total damages, if both defendants are found liable, which occurs with probability $\delta p^{2}$; plus all of the total damages, if he is found liable while his codefendant is found not liable, which happens with probability $p(1-\delta p)$; in addition, $D_{i}$ will pay trial costs of $t$. If $s_{i}$ is less than this amount, then $D_{i}$ prefers to settle. On the other hand, if $D_{i}$ is expected to settle for $s_{i}$, then $D_{j}$ can expected to pay the full amount of the damages offset by the amount of the settlement with $D_{i}$ if $D_{j}$ is found liable, which occurs with probability $p$; in addition, $D_{j}$ will pay trial costs of $t$. If $s_{j}$ exceeds this amount, then $D_{j}$ will indeed prefer trial. 
Finally, given a pair of demands $\left(s_{1}, s_{2}\right)$, it will be a Nash equilibrium for both $D_{1}$ and $D_{2}$ to reject their respective demands if and only if $s_{i} \geq .5 \delta p^{2}(2 d)+p(1-\delta p)(2 d)+t$, for $i=1,2$. In this case, each defendant prefers to go to trial (given that the other defendant is expect to go to trial as well) rather than to acquiesce to the plaintiff's demand.

We now consider $P$ 's optimal settlement demand pair $\left(s_{1}, s_{2}\right)$. We assume that whenever it is a Nash equilibrium for both $D_{1}$ and $D_{2}$ to accept their respective demands, they do so. ${ }^{29}$ This simplifies the exposition, and ensures that any trials that occur are not the result of coordination failure. Moreover, it can be shown that, from $P$ 's point of view, a pair of settlement demands which induces acceptance by only one $D$ is always dominated by either a demand pair which induces both $D$ s to accept or by a demand pair that induces both $D$ s to reject. Thus, we need only ask: what settlement demand pair maximizes $P$ 's expected payoff from settlement with both $D$ s, and (2) when is the resulting expected payoff better than what she expects from trial against $D$ s?

To answer the first question, we define $P$ 's maximized return from inducing both $D$ s to accept their respective settlement demands as $V^{P}(A, A)=\max s_{1}+s_{2}$ subject to: $s_{i} \leq p\left(2 d-s_{j}\right)+t$, for $i=1,2$. The graph below illustrates the combination of settlement demands that satisfy the constraints, and the line which provides the highest feasible combined settlement value $s_{1}+s_{2}$. It is clear that $P$ 's most-preferred settlement pair consists of $\left(s_{1}, s_{2}\right)=\left(s^{*}, s^{*}\right)$, where the two constraints intersect. This settlement demand is $s^{*}=(2 p d+t) /(1+p)$, which yields the payoff $V^{P}(A, A)=2(2 p d+t) /(1+p)$. Alternatively, if $P$ induces both $D$ s to choose trial, she can expect to receive $V^{P}(R, R)=\delta p^{2}(2 d)+2 p(1-\delta p)(2 d)-2 t=2 p d(2-\delta p)-2 t$. This payoff reflects the fact that $P$ collects the full damages $2 d$ if she prevails against either $D$, or both; however, she pays the trial costs $2 t$.

To answer the second question, we compare the payoffs $V^{P}(A, A)$ and $V^{P}(R, R)$. It is straightforward to show that $V^{P}(A, A) \gtreqless V^{P}(R, R)$ as $\delta \gtreqless \delta^{*} \equiv\left(2 p^{2} d-t(2+p)\right) / p^{2}(1+p)$. Notice that $\delta^{*}<1 / p$ always holds, but $\delta^{*}>1$ if and only if $t<p^{2} d(1-p) /(2+p)$. Thus, we conclude that if $t \geq p^{2} d(1-p) /(2+p)$, then all cases will settle under joint and several liability and $P$ 's equilibrium payoff will be given by $V_{J S L}^{P}=V^{P}(A, A)$. However, if $t<p^{2} d(1-p) /(2+p)$, then cases that

\footnotetext{
${ }^{29}$ For some parameters, there may be multiple equilibria (e.g., one in which both defendants accept and one in which both reject; or two asymmetric equilibria in which one defendant accepts and the other rejects). KR discuss this issue in detail; in a related paper to be discussed below, Spier (2002) uses risk dominance to select among equilibria.
} 


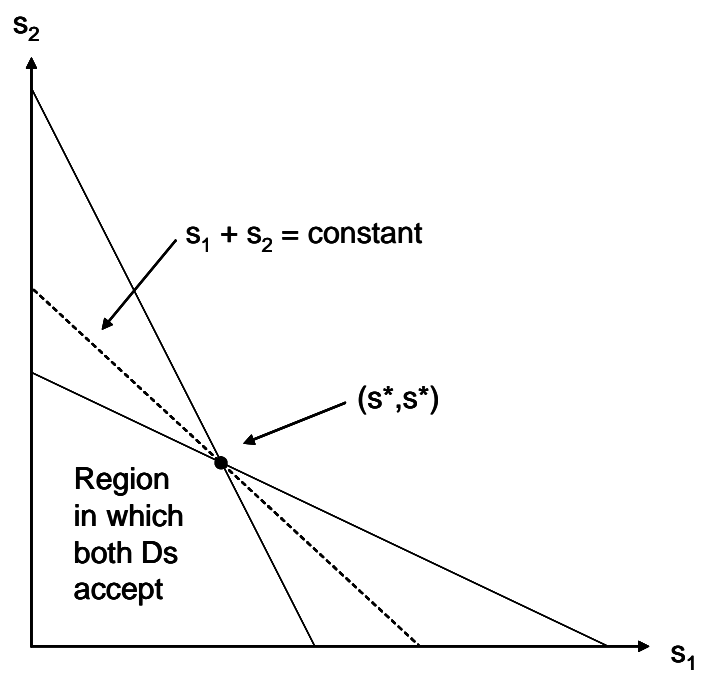

are sufficiently highly-correlated will settle, but $P$ will go to trial against both $D$ s if the cases are sufficiently uncorrelated. Thus, $V_{J S L}^{P}=V^{P}(R, R)$ for $\delta \leq \delta^{*}$ and $V_{J S L}^{P}=V^{P}(A, A)$ for $\delta \geq \delta^{*}$.

This occurs because $P$ gets "two bites at the apple" when she goes to trial against both $D$ s, and the extra bite is most valuable when the cases are uncorrelated. On the other hand, this "extra bite" feature also lets $P$ demand more in settlement, since going to trial against a single $D$ is a more potent threat (where he may have to pay the total amount of damages). This raises the question of whether $P$ always prefers to sue under JSL rather than non-joint liability (hereafter, NJL). Under NJL, there are two separate bilateral bargaining problems. Assuming that each $D$ is responsible for half of the total harm, $P$ can successfully demand $p d+t$ from each $D$, for a total payoff of $V_{N J L}^{P}=2(p d+t)$. It turns out that a sufficient condition for $P$ to prefer JSL to NJL is $t<(1-p) d .^{30}$

Feess \& Muehlheusser (2000) provide an asymmetric information model in which each defendant's type is independently drawn; a "bad" type is more likely to be found liable than a "good" type. The plaintiff makes a pair of demands, and each defendant accepts or rejects the demand made of him; thus, this is a screening model. They find that three types of equilibria exist, depending on the parameters. There are equilibria in which $P$ makes the same demand of both $D$ 's, and either (a) both types of $D$ settle; or (b) the "bad" type settles and the "good" type goes to

\footnotetext{
${ }^{30}$ If $t \geq p^{2} d(1-p) /(2+p)$, then all cases settle under both JSL and NJL. Comparison of $V_{J S L}^{P}=V^{P}(A, A)$ with $V_{N J L}^{P}$ indicates that $P$ will prefer JSL to NJL if and only if $t<(1-p) d$. On the other hand, if $t<p^{2} d(1-p) /(2+p)$, then it is surely true that $t<(1-p) d$. This is a sufficient condition for $P$ to prefer JSL to NJL for all $\delta$, taking into account the fact that $V_{J S L}^{P}=V^{P}(R, R)$ for $\delta \leq \delta^{*}$ and $V_{J S L}^{P}=V^{P}(A, A)$ for $\delta \geq \delta^{*}$.
} 
trial. Finally, there are equilibria in which $P$ makes a high demand of one $D$ and a low demand of the other; the $D$ facing the low demand settles for sure, while the $D$ facing the high demand settles if he is "bad" and goes to trial if he is "good." As in the usual screening model, it is never an equilibrium for $P$ to go to trial against both types of $D$; nevertheless, both cases can end up at trial (as in equilibrium (b) above).

Two strands of literature related to KR have been developed, but they are outside the purview of this survey. First, Donohue (1994) argues that full settlement can be restored if the plaintiff makes contingent demand; if either defendant fails to accept, the plaintiff goes to trial against both). Klerman (1996) suggests that settlement incentives can be restored by using a conditional pro tanto setoff rule, which specifies that the amount of a previous settlement with $D_{1}$ reduces the liability of $D_{2}$ at trial only if $D_{1}$ would have been found liable at trial. However, Feess \& Muehlheusser (2000) argue that the conditional pro tanto setoff rule loses its dominance when each defendant has private information about his likelihood ("high" or "low") of being found liable. Second, Spier (1994) and Kahan (1996) discuss the effect of settlement under JSL on care taken in the primary activity.

\subsection{Insolvency}

Spier (2002) describes another settlement negotiation scenario that involves externalities, and has a formal structure quite similar to the one just described. This situation arises when a single defendant has harmed two plaintiffs, but does not have enough wealth to compensate both plaintiffs; indeed, we will consider the case in which the defendant does not have enough wealth to fullycompensate even one plaintiff, since the commonalities with the KR model are most evident when the defendant's insolvency problem is extreme (see Spier, 2002, for the more general model, as well as several extensions). In particular, we will retain all of the notation used above, but the defendant's wealth, denoted $w$, will replace the total damages $2 d$ from above. ${ }^{31}$ In addition, Spier assumes that the defendant, denoted $D$, makes simultaneous settlement offers to the plaintiffs, denoted $P_{1}$ and $P_{2}$, who simultaneously and non-cooperatively decide whether to accept or reject the offers. Of course, if $P_{i}$ accepts her offer, this reduces the amount that $P_{j}$ can expect to obtain

\footnotetext{
${ }^{31}$ Note that $w$ represents the wealth available for compensating victims; the defendant is assumed to pay trial costs from some separate fund. Kornhauser \& Revesz (1994b) conduct their analysis of insolvency under the assumption of zero trial costs, so this issue does not arise.
} 
at trial, just as in the unconditional pro tanto setoff rule.

Given a pair of offers $\left(s_{1}, s_{2}\right)$, it will be a Nash equilibrium for both $P_{1}$ and $P_{2}$ to accept their respective offers if and only if $s_{i} \geq p\left(w-s_{j}\right)-t$, for $i=1,2$. This is because, given that $P_{j}$ is expected to accept $s_{j}, P_{i}$ can expect to receive the defendant's total wealth less the amount of the settlement with $P_{j}$, should $P_{i}$ prevail at trial (which occurs with probability $p$ ); in addition, $P_{i}$ will pay trial costs of $t$. Thus, $P_{i}$ will prefer to accept any settlement demand $s_{i} \geq p\left(2 d-s_{j}\right)-t$.

Given a pair of offers $\left(s_{1}, s_{2}\right)$, it will be a Nash equilibrium for $P_{i}$ to accept $s_{i}$ and $P_{j}$ to reject $s_{j}$ if and only if $s_{i} \geq .5 \delta p^{2} w+p(1-\delta p) w-t$ and $s_{j} \leq p\left(w-s_{i}\right)-t$. This is because, given that $P_{j}$ is expected to reject $s_{j}$ and go to trial, $P_{i}$ can choose to go to trial as well, in which case $P_{i}$ can expect to receive her share (half) of the defendant's wealth if both plaintiffs prevail, which occurs with probability $\delta p^{2}$; plus all of the defendant's wealth if $P_{i}$ prevails but $P_{j}$ does not, which happens with probability $p(1-\delta p)$; however, $P_{i}$ will pay trial costs of $t$. If $s_{i}$ exceeds this amount, then $P_{i}$ prefers to settle. On the other hand, if $P_{i}$ is expected to settle for $s_{i}$, then $P_{j}$ can expected to receive the defendant's total wealth offset by the amount of the settlement with $P_{i}$ if $P_{j}$ prevails at trial, which occurs with probability $p$; however, $P_{j}$ will pay trial costs of $t$. If $s_{j}$ is less than this amount, then $P_{j}$ will indeed prefer trial.

Finally, given a pair of offers $\left(s_{1}, s_{2}\right)$, it will be a Nash equilibrium for both $P_{1}$ and $P_{2}$ to reject their respective offers if and only if $s_{i} \leq .5 \delta p^{2} w+p(1-\delta p) w-t$, for $i=1,2$. In this case, each plaintiff prefers to go to trial (given that the other plaintiff is expect to go to trial as well) rather than to accept the defendant's offer.

As before, we assume that whenever there is a Nash equilibrium in which both plaintiffs accept their offers, this equilibrium is selected. Also as before, it can be shown that a settlement offer pair that induces $P_{i}$ to accept and $P_{j}$ to reject is always dominated by either an offer pair which induces both to accept or by an offer pair that induces both to reject. Thus, we need only ask: (1) what settlement offer pair minimizes $D$ 's expected cost from settlement with both $P$ s, and (2) when is the resulting expected cost lower than what he expects from trial against both Ps?

$D$ 's minimized expected cost from inducing both $P$ s to accept their respective settlement offers is $V^{D}(A, A)=\min s_{1}+s_{2}$ subject to: $s_{i} \geq p\left(w-s_{j}\right)-t$, for $i=1,2$. The graph below illustrates the combination of settlement offers that satisfy the constraints, and the line which provides the lowest feasible combined settlement value $s_{1}+s_{2}$. It is clear that $D$ 's least-cost offer pair consists 
of $\left(s_{1}, s_{2}\right)=\left(s^{* *}, s^{* *}\right)$, where the two constraints intersect. This settlement offer is $s^{* *}=(p w-$ $t) /(1+p)$, which yields the payoff $V^{D}(A, A)=2(p w-t) /(1+p)$. Alternatively, if $D$ induces both $P$ s to reject his demands, he can expect to pay the amount $V^{D}(R, R)=\delta p^{2} w+2 p(1-\delta p) w+2 t=$ $p w(2-\delta p)+2 t$. This payoff reflects the fact that $D$ forfeits his entire wealth $w$ if either $P$ prevails, or both; in addition he pays the trial costs $2 t$.

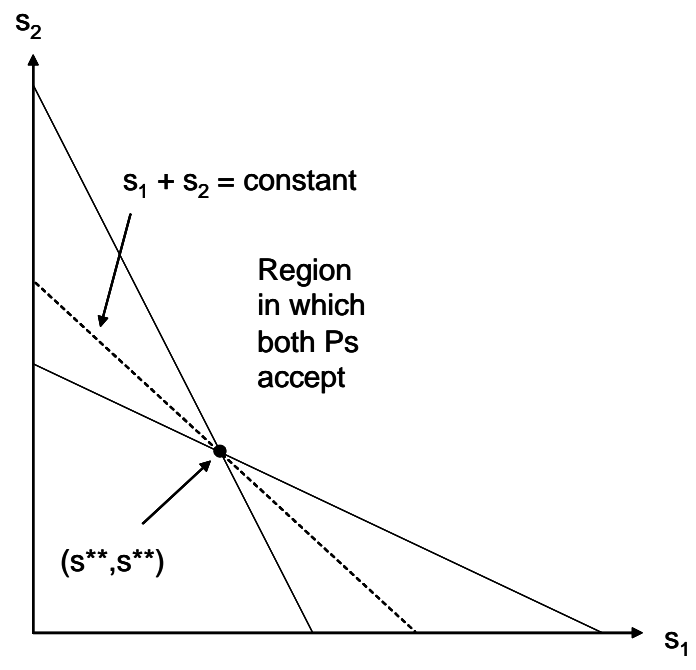

We now compare the payoffs $V^{D}(A, A)$ and $V^{D}(R, R)$. It is straightforward to show that $V^{D}(A, A) \gtreqless V^{D}(R, R)$ as $\delta \gtreqless \delta^{* *} \equiv\left(2 p^{2} w+2 t(2+p)\right) / p^{2} w(1+p)$. Notice that $\delta^{* *}>1$ always holds, but $\delta^{*}<1 / p$ holds if and only if $t<p w(1-p) / 2(2+p)$. Thus, we conclude that if $t \geq p w(1-$ $p) / 2(2+p)$, then all cases will settle when $D$ is insolvent, and $D$ 's equilibrium payoff will be given by $V_{I N S}^{D}=V^{D}(A, A)$. However, if $t<p w(1-p) / 2(2+p)$, then cases that are sufficiently highlycorrelated will go to trial, but $D$ will settle with both $P$ s if the cases are sufficiently uncorrelated. Thus, $V_{I N S}^{D}=V^{D}(A, A)$ for $\delta \leq \delta^{* *}$ and $V_{I N S}^{D}=V^{D}(R, R)$ for $\delta \geq \delta^{* *}$.

Note the similarities to (and differences from) the KR model: here the acceptance versus rejection constraints involve (1) a reversed inequality; (2) the substitution of $w$ for $2 d$; and (3) the subtraction, rather than the addition, of $t$. Here, the defendant's payoff differs from that of the plaintiff in KR by the substitution of $w$ for $2 d$ and by the addition, rather than the subtraction, of the trial costs $2 t$; moreover, here the defendant wants to minimize his expected costs, while the plaintiff in KR wants to maximize her expected payoff. Finally, here settlement negotiations fail when the cases are sufficiently correlated, while in KR they fail when the cases are sufficiently 
uncorrelated.

\section{Summary}

Recent work on the economics of settlement bargaining has emphasized multiple litigant settlement negotiation. The essential feature of such bargaining is that seemingly bilateral negotiations affect, and are affected by, simultaneous or sequential settlement possibilities with other litigants. We sub-divided this sampling of the literature into two groupings. In the first grouping, we considered papers wherein discretionary choices by one or more of the litigants (to create, or capitalize on, possible linkages among yet other litigants) generate such externalities. In that section the preferences of the litigants over the use of such devices need not be directly opposed.

The second grouping emphasized examples wherein the employment of existing legal doctrine or rules of procedure may induce bargaining externalities. We noted that the choice by one or another of the litigants to make use of the relevant legal doctrines or procedural rules may be voluntary, but in this second grouping preferences of the individual litigants over the use of such doctrines and procedures are usually diametrically opposed; such rules exist to provide recourse when agreement is not possible.

In both types of analyses formal models, relying on game theory and information economics, have been used to understand what attributes of such multi-litigant bargaining are privately and/or socially advantageous (or disadvantageous), and when such devices, doctrines or rules lead to a greater or lesser extent of settlement. 


\section{References}

Ashcraft v. Conoco, Inc. 1998 U.S. Dist. LEXIS 4092

Bebchuk LA. 1984. Litigation and settlement under imperfect information. RAND J. Econ. 15:404-15

Binmore K. 1992. Fun and games: a text on game theory. Lexington, MA: D.C. Heath and Company

Briggs HC III, Huryn KD, McBride ME. 1996. Treble damages and the incentive to sue and settle. RAND J. Econ. 27:770-86

Che YK. 1996. Equilibrium formation of class action suits. J. Public Econ. 62:339-61

Che YK. 2002. The economics of collective negotiation in pretrial bargaining. Int. Econ. Rev. $43: 549-75$

Che YK, Yi JG. 1993. The role of precedents in repeated litigation. J. Law, Econ., Organ. 9:399-424

Choi JP. 1998. Patent litigation as an information transmission mechanism. Am. Econ. Rev. 88:1249-63

Daughety AF, Reinganum, JF. 1994. Settlement negotiations with two-sided asymmetric information: model duality, information distribution, and efficiency. Int. Rev. Law Econ. 14:283-98

Daughety AF, Reinganum, JF. 1999. Hush money. RAND J. Econ. 30:661-78

Daughety AF, Reinganum, JF. 2002. Informational externalities in settlement bargaining: confidentiality and correlated culpability. RAND J. Econ. 33:587-604

Daughety AF, Reinganum, JF. 2004. Exploiting future settlements: a signalling model of mostfavored-nation clauses in settlement bargaining. RAND J. Econ. 35:467-85

Donohue JJ. III. 1994. The effect of joint and several liability on the settlement rate - mathematical symmetries and metaissues about rational litigant behavior: comment on Kornhauser and Revesz. J. Legal Stud. 23:543-58

Feess E, Muehlheusser G. 2000. Settling multidefendant lawsuits under incomplete information. Int. Rev. Law Econ. 20:295-313

Gould JP. 1973. The economics of legal conflicts. J. Legal Stud. 2:279-300

Hare FH, Gilbert JL, ReMine WH. 1988. Confidentiality orders. New York: John Wiley and 
Sons

Kahan M. 1996. The incentive effects of settlements under joint and several liability. Int. Rev. Law Econ. 16:389-395

Klerman D. 1996. Settling multidefendant lawsuits: the advantage of conditional setoff rules. $J$. Legal Stud. 25:445-62

Kornhauser LA, Revesz RL. 1994a. Multidefendant settlements: the impact of joint and several liability. J. Legal Stud. 23:41-76

Kornhauser LA, Revesz RL. 1994b. Multidefendant settlements under joint and several liability: the problem of insolvency. J. Legal Stud. 23:517-42

Landes WM. 1971. An economic analysis of the courts. J. Law Econ. 14:61-107

Mas-Colell A, Whinston MD, Green J. 1995. Microeconomic theory. New York: Oxford University Press

Muthoo A. 1999. Bargaining theory with applications. Cambridge, UK: Cambridge University Press

Posner RA. 1973. An economic approach to legal procedure and judicial administration. J. Legal Stud. 2:399-458

Reinganum JF, Wilde LF. 1986. Settlement, litigation, and the allocation of litigation costs. RAND J. Econ. 17:557-66

Schweizer U. 1989. Litigation and settlement under two-sided incomplete information. Rev. Econ. Stud. 56:163-77

Shavell S. 1982. Suit, settlement and trial: a theoretical analysis under alternative methods for the allocation of legal costs. J. Legal Stud. 11:55-81

Spier KE. 1994. A note on joint and several liability: insolvency, settlement, and incentives. $J$. Legal Stud. 23:559-68

Spier KE. 2002. Settlement with multiple plaintiffs: the role of insolvency. J. Law, Econ., Organ. 18:295-323

Spier KE. 2003a. The use of most-favored-nation clauses in settlement of litigation. RAND J. Econ. 34:78-95

Spier KE. 2003b. Tied to the mast: most-favored-nation clauses in settlement contracts. $J$. Legal Stud. 32:91-120 
Viscusi WK. 2002. Smoke-filled rooms - a postmortem on the tobacco deal. Chicago: The University of Chicago Press

Yang BZ. 1996. Litigation, experimentation, and reputation. Int. Rev. Law Econ. 16:491-502 